\title{
Further Analysis Is Required to Identify an Early Stopping Rule for Peginterferon Therapy That Is Valid for All Hepatitis B e Antigen-Positive Patients
}

To the Editor:

We read with interest the article by Sonneveld et al., ${ }^{1}$ who reported an association between on-treatment hepatitis B surface antigen (HBsAg) levels and a sustained response to peginterferon alfa-2b in hepatitis $\mathrm{B}$ e antigen (HBeAg)-positive patients $(\mathrm{n}=$ 221). No HBsAg decline by week 12 of therapy was associated with a low chance of a sustained response $(97 \%$ probability of nonresponse) and was proposed as an early stopping rule for peginterferon therapy. Because this rule needs to be validated in other studies, we investigated how the rule would have performed in $\mathrm{HBeAg}$-positive patients treated with peginterferon alfa-2a during two independent, large-scale studies. ${ }^{2,3}$

$\mathrm{HBeAg}$-positive patients received peginterferon alfa-2a $(180 \mu \mathrm{g} /$ week) with or without lamivudine $(100 \mathrm{mg} /$ day $)$ for 48 weeks as part of a phase $3 \operatorname{study}^{2}(\mathrm{n}=542)$ or peginterferon alfa-2a (180 $\mu \mathrm{g} /$ week) for 48 weeks as part of the Nephrotic Syndrome Study Network (NEPTUNE) study $(\mathrm{n}=136) .{ }^{3}$ Overall, the rates of $\mathrm{HBeAg}$ loss and hepatitis B virus (HBV) DNA levels $<10,000$ copies/mL in the phase 3 and NEPTUNE peginterferon alfa-2a studies were similar ( $25 \%$ and $24 \%$, respectively), and they were higher than those in Sonneveld et al.'s analysis (19\%). ${ }^{1}$ In accordance with Sonneveld et al.'s data, the HBsAg decline was more pronounced in patients with a response 6 months post-treatment versus nonresponders. Patients with no $\mathrm{HBsAg}$ decline from the baseline to week 12 had $82 \%(80 / 97)$ and $71 \%(22 / 31)$ probabilities of nonresponse in the phase 3 and NEPTUNE studies, respectively; these were considerably lower than the probability of $97 \%$ in Sonneveld et al.'s study (Fig. 1). The probabilities of response in patients with no HBsAg decline were 18\% (17/97) and 29\% (9/ 31 ), respectively. Applying the stopping rule would have resulted in premature treatment discontinuation in some patients (17 and 9, respectively) who would have responded. $\mathrm{HBeAg}$ seroconversion
6 months post-treatment, rather than $\mathrm{HBeAg}$ loss and HBV DNA levels $<10,000$ copies/mL, was the primary endpoint in the peginterferon alfa-2a studies. Using this more robust indicator of sustained immune control would have resulted in some patients in the phase 3 and NEPTUNE studies (30 and 12, respectively) discontinuing their treatment prematurely if the stopping rule had been applied.

Differences in the study populations could explain the varying response rates and the fact that the proposed stopping rule could not be validated by the peginterferon alfa- $2 \mathrm{a}$ analyses. Sonneveld et al.'s analysis ${ }^{1}$ was a European study in which only $20 \%$ of the patients were Asian, whereas the populations of the phase 3 and NEPTUNE peginterferon alfa-2a studies were predominantly Asian $(>80 \%)$. This influenced the genotype distribution; Sonneveld et al.'s study had a high proportion of genotype A or D patients, whereas the peginterferon alfa-2a studies included predominantly genotype $\mathrm{B}$ and $\mathrm{C}$ patients. In combination with the differences in the treatment regimens (peginterferon alfa- $2 \mathrm{a}$ versus peginterferon alfa- $2 \mathrm{~b}$ and 48 weeks of therapy versus 52 weeks) and in the numbers of patients included in the analyses, this may account for the differences in the results.

Monitoring $\mathrm{HBsAg}$ levels during peginterferon therapy provides a good indication of the treatment response and helps in identifying early success. However, it is clear that further analysis is required either to identify an early stopping rule for peginterferon therapy that is valid for all genotypes or to develop genotype-specific algorithms.

\author{
Teerha Piratvisuth, M.D. ${ }^{1}$ \\ Patrick Marcellin, M.D. ${ }^{2}$ \\ ${ }^{1}$ NKC Institute of Gastroenterology and Hepatology \\ Songklanagarind Hospital \\ Prince of Songkla University \\ Hat Yai, Thailand
}

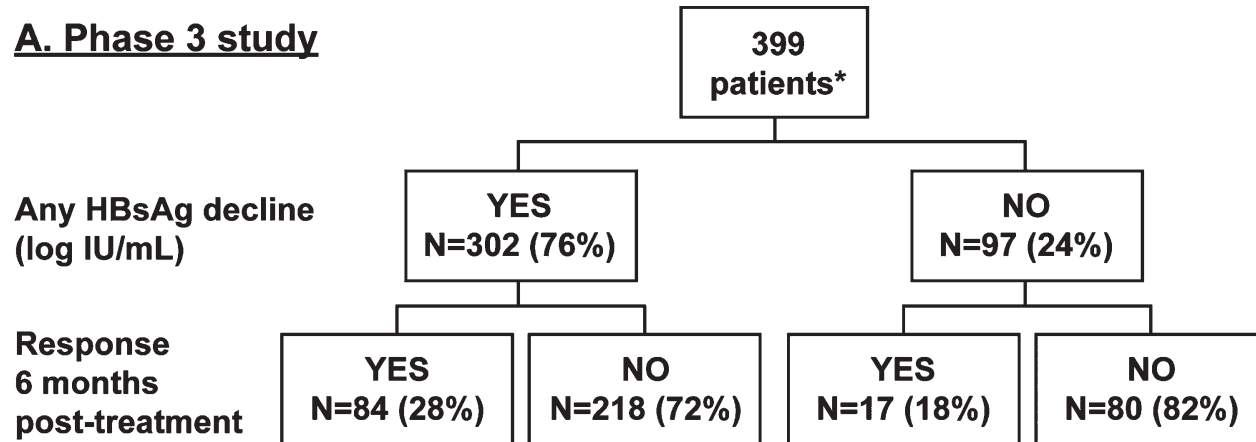

\section{B. NEPTUNE study}

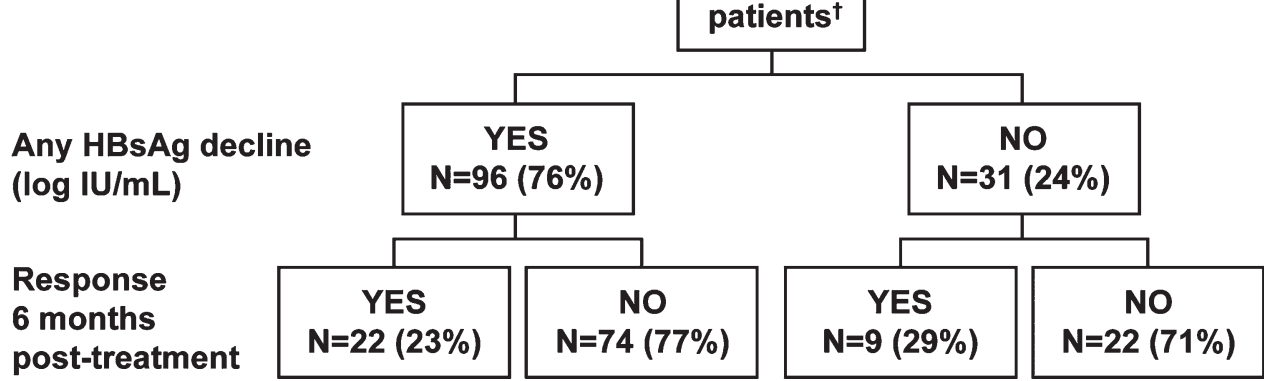

Fig. 1. Flowcharts for any decline in HBsAg levels from the baseline to week 12 with respect to the sustained response posttreatment. Response is defined as HBeAg loss and HBV DNA levels $<10,000$ copies $/ \mathrm{mL}$. An asterisk indicates patients with $\mathrm{HBsAg}$ values available for the baseline, for weeks 12, 24, and 48 of therapy, and for 6 months post-treatment. A dagger indicates patients with $\mathrm{HBsAg}$ values available for the baseline and for week 12 of therapy. 
${ }^{2}$ Service d'Hépatologie

Centre de Recherche Biologique Bichat Beaujon (Unité 773) Hopital Beaujon University of Paris, Clichy, France

\section{References}

1. Sonneveld MJ, Rijckborst V, Boucher CA, Hansen BE, Janssen HL. Prediction of sustained response to peginterferon alfa- $2 b$ for $\mathrm{HBeAg}$-positive chronic hepatitis B using on-treatment HBsAg decline. Hepatology 2010;52:1251-1257.

2. Lau GK, Piratvisuth T, Luo KX, Marcellin P, Thongsawat S, Cooksley G, et al. Peginterferon alfa-2a, lamivudine, and the combination for $\mathrm{HBeAg}$ positive chronic hepatitis B. N Engl J Med 2005;352:2682-2695.

3. Liaw Y-F, Xie Q, Han KH, Gane EJ, Piratvisuth T, McCloud PI, et al. Shorter duration and lower dose of peginterferon alfa-2a therapy results in inferior $\mathrm{HBeAg}$ seroconversion rates compared with the duration and dose of 48 weeks and $180 \mu \mathrm{g}$ : NEPTUNE study. Paper presented at: 61st Annual Meeting of the American Association for the Study of Liver Diseases; October 29-November 2, 2010; Boston, MA.

This work was supported by a research grant from F. Hoffmann-La Roche (Basel, Switzerland).

Editorial support was provided by Dr. Liesje Thomas (Elements Communications, Ltd., Westerham, United Kingdom) and was funded by F. Hoffmann-La Roche (Basel, Switzerland).

Copyright (C) 2010 by the American Association for the Study of Liver Diseases. View this article at wileyonlinelibrary.com.

DOI 10.1002/hep.24136

Potential conflict of interest: Dr. Piratvisuth advises, serves on the speakers' bureau of, and received grants from Roche and Novartis. Dr. Piratvisuth advises and serves on the speakers' bureau of GlaxoSmithKline and MSD. Dr. Piratvisuth also serves on the speakers' bureau of Bristol-Myers Squibb.

Dr. Marcellin serves on the speakers' bureau of, advises, and received grants from Roche, Schering Plough, and Gilead. Dr. Marcellin advises and serves on the speakers' bureau of Bristol-Myers Squibb, Vertex, Novartis, Tibotec, and Intermune. Dr. Marcellin also advises Pharmasset, MSD, Boehringer, Biolex, and Zymogenetics.

\section{Reply}

We thank Piratvisuth and Marcellin for their valuable contribution to the debate. First of all, it is important to note that our findings of a more pronounced hepatitis $\mathrm{B}$ surface antigen ( $\mathrm{HBsAg})$ decline in hepatitis $\mathrm{B}$ e antigen ( $\mathrm{HBeAg}$ )-positive patients with a response to peginterferon were confirmed in their study, reflecting the induction of an immune response in these patients. ${ }^{1}$

Their analysis shows that failure to achieve a decline in $\mathrm{HBsAg}$ levels through 12 weeks of therapy does not predict nonresponse as well in their cohort as it did in our study. Possible explanations for these discrepant findings could be the type of peginterferon or duration of therapy, as suggested by Piratvisuth and Marcellin. However, the most probable explanation is the difference in hepatitis B virus (HBV) genotype distribution between the study cohorts. Pre- liminary data from our group show that $\mathrm{HBsAg}$ decline among $\mathrm{HBeAg-positive} \mathrm{patients} \mathrm{treated} \mathrm{with} \mathrm{peginterferon} \mathrm{is} \mathrm{strongly} \mathrm{related}$ to HBV genotype. ${ }^{2}$ These differences across genotypes, particularly among patients who fail to achieve a response, may be an important determinant of the performance of a threshold-based stopping rule. Consequently, the performance of any threshold is primarily dependent upon the distribution of HBV genotypes in the study cohort.

The importance of HBV genotype when applying stopping rules for peginterferon therapy in chronic hepatitis B was recently illustrated by a validation study of our stopping rule for HBeAg-negative patients. This stopping rule, recommending discontinuation of peginterferon in patients who fail to achieve a decline in $\mathrm{HBsAg}$ and a decline in HBV DNA of $>2 \log$ at week 12, was based on a cohort of mostly genotype $\mathrm{D}$ patients. ${ }^{3}$ When validated in two independent study cohorts, performance was best in genotype D patients treated with either 48 or 96 weeks of peginterferon. ${ }^{4}$

In conclusion, monitoring of $\mathrm{HBs} A \mathrm{~g}$ levels during peginterferon therapy of chronic hepatitis $\mathrm{B}$ may provide valuable insight into a patient's probability of achieving a response. However, it appears that differences in HBsAg decline across HBV genotypes have to be taken into consideration. A pooled analysis of the data from our respective studies, stratified by $\mathrm{HBV}$ genotype and possibly incorporating HBV DNA levels, appears to be a crucial next step.

\author{
MiLAN J. SONNEVELD \\ VINCENT RIJCKBORST \\ HARRY L.A. JANSSEN \\ Department of Gastroenterology and Hepatology, Erasmus MC \\ University Medical Center, Rotterdam, The Netherlands
}

\section{References}

1. Sonneveld MJ, Rijckborst V, Boucher CA, Hansen BE, Janssen HL. Prediction of sustained response to peginterferon $a l f a-2 b$ for hepatitis $B$ e antigen-positive chronic hepatitis B using on-treatment hepatitis B surface antigen decline. Hepatology 2010;52:1251-1257.

2. Sonneveld MJ, Rijckborst V, Senturk H, Zeuzem S, Akarca U, Simon $\mathrm{K}$, et al. $\mathrm{HBsAg}$ decline during peginterferon alfa-2b therapy for HBeAg-positive chronic hepatitis B depends on HBV genotype: relation to sustained response [Abstract 441]. Hepatology 2010;52(Suppl.).

3. Rijckborst V, Hansen BE, Cakaloglu Y, Ferenci P, Tabak F, Akdogan M, Simon K, et al. Early on-treatment prediction of response to peginterferon alfa-2a for HBeAg-negative chronic hepatitis B using HBsAg and HBV DNA levels. Hepatology 2010;52:454-461.

4. Rijckborst V, Hansen B, Ferenci P, Brunetto M, Tabak F, Cakaloglu Y, et al. Early on-treatment HBsAg and HBV DNA levels identify HBeAgnegative patients not responding to 48 or 96 weeks of peginterferon alfa-2a therapy [Abstract 479]. Hepatology 2010;52(Suppl.).

Copyright $\odot 2010$ by the American Association for the Study of Liver Diseases.

View this article at wileyonlinelibrary.com.

DOI 10.1002/hep.24182

Potential conflict of interest: H.L.A. Janssen received grants from and is a consultant for Bristol-Myers Squibb, Gilead Sciences, Novartis, Roche, and Schering-Plough. Vincent Rijckborst is a consultant for Roche.

\section{Optimal Duration of Treatment for Acute Hepatitis C in Human Immunodeficiency Virus-Positive Individuals?}

\section{To the Editor:}

In a recent article, Piroth et al. ${ }^{1}$ report on the outcomes following treatment of acute hepatitis $\mathrm{C}$ in 40 human immunodeficiency virus (HIV)-positive men who have sex with men (MSM), 38 of whom received combination therapy with pegylated interferon and ribavirin (the HEPAIG study). The overall sustained viral response (SVR) rate of $82 \%$ is encouraging, especially given that $81 \%$ of their cohort had genotype (GT) 1 or 4 infection, and supports guidelines for recommending treatment in this setting. ${ }^{2}$ However, we question 
the conclusions the authors draw from their data regarding optimal duration of therapy.

The authors argue that those patients treated for longer than 28 weeks had a significantly greater SVR rate than those treated for less than 28 weeks $(92 \%$ versus $64 \%$, respectively, $P=0.03)$, and that the rate of SVR $(25 \%)$ in those who did not achieve rapid virological response (RVR) but received $<28$ weeks of therapy merits extension to 48 weeks for all patients with non-RVR. The evidence for these specific recommendations, however, is weak and confused by how data from the "null responder" group is dealt with in this nonrandomized design. Five patients were reported as "never responding" to therapy presumably defined as no RVR or early viral response (EVR) and ceased therapy before 28 weeks. In the analysis examining SVR rates the authors appear to have included these subjects in the group receiving less than 28 weeks (SVR 9/14, 64\%) versus longer duration (SVR 23/25, 92\%) resulting in the "short arm" appearing to be inferior. In fact the true question to examine is how common relapse was in non-RVR subjects who then achieved EVR and were subsequently treated for less than 28 weeks. A high rate of relapse in this situation would suggest an inadequate length of treatment course. In the HEPAIG study it appears that 13 nonRVR patients subsequently achieved EVR but only one of these was treated for $<28$ weeks and this patient subsequently achieved SVR.

In the Australian Trial in Acute Hepatitis C (ATAHC), 35 HIV-positive MSM were treated with 24 weeks combination therapy with pegylated interferon and ribavirin and RVR was achieved in $12(34 \%) .^{3}$ In the 23 non-RVR subjects, three had no EVR and were discontinued and of the remaining 20 (50\% GT 1), only three (2 GT 1 and 1 GT 3) relapsed after treatment completion, demonstrating that 24 weeks of combination therapy was adequate in $85 \%$ of subjects with no RVR but EVR. Given the additional expense and toxicity of extending therapy to 48 weeks (we note the $40 \%$ use of growth factors in HEPAIG), the costs would outweigh any potential marginal benefit. The HEPAIG study recommendation is even less appealing given the likelihood of new therapies available for retreatment within the next few years for those who do relapse.

In summary, we agree with the HEPAIG authors that combination therapy is optimal in this setting and that treatment should be discontinued in those with complete nonresponse at week 12 . However, we believe their treatment duration recommendations are not based on available evidence and that this question therefore remains unanswered.

\section{Gail V. Matthews, MBChB (UK) PhD \\ Gregory J. Dore, MD PHD \\ Viral Hepatitis Clinical Research Program \\ National Centre in HIV Epidemiology and Clinical Research University of New South Wales, Sydney, Australia}

\section{References}

1. Piroth L, Larsen C, Binquet C, et al. Treatment of acute hepatitis C in human immunodeficiency virus-infected patients: the HEPAIG study. Hepatology 2010;52:1915-1921.

2. Rockstroh J. Acute hepatitis C in HIV-infected individuals-recommendations from the NEAT consensus conference. AIDS. Epub ahead of print, Jan 03, 2011.

3. Dore GJ, Hellard M, Matthews G, et al. Effective treatment of injecting drug users with recently acquired hepatitis $\mathrm{C}$ virus infection. Australian Trial In Acute Hepatitis C Study Group. Gastroenterology 2010;138: 123-135.e2.

Copyright $(2010$ by the American Association for the Study of Liver Diseases. View this article at wileyonlinelibrary.com.

DOI 10.1002/hep.24152

Potential conflict of interest: Nothing to report.

\section{Reply}

We thank Matthews and Dore for agreeing with our suggestion to treat human immunodeficiency virus (HIV)-infected patients with acute hepatitis $\mathrm{C}$ by using combination therapy, ${ }^{1}$ although they advocate a 24 -week duration because $85 \%$ of their patients with early virological response (EVR) but not rapid virological response (RVR) achieved sustained virological response (SVR) after a 24-week course in the recent ATAHC study. ${ }^{2}$ This is a key point, because the optimal duration would be the best compromise between reducing expense and toxicity on the one hand, and maximal efficacy on the other hand, given the faster and more severe evolution of HCV infection in HIV-infected patients.

We agree that excluding patients who failed in the HEPAIG study to achieve RVR or EVR $(n=4)$ would enhance the SVR rate of 24-week course therapy. Indeed, the SVR rate in patients experiencing EVR, when assessed, was $88 \%$ (8/9), which is higher than that observed in ATAHC $(74 \%)^{2}$ and close to the $92 \%$ obtained with a longer course in HEPAIG. ${ }^{1}$ However, the RVR rate in HEPAIG was high, particularly for the 14 patients treated for $24 \pm 4$ weeks $(57 \%)$, compared with that observed in ATAHC (34\%), whereas the EVR rate was lower (75\% versus 91\%). Because HCV therapy and doses were similar in these studies, this may be linked to differences in HCV genotype distribution (with a potential cluster effect), in the clinical presentation of acute hepatitis $\mathrm{C}$, or in the characteristics of the patients (e.g., the HCV transmission route and perhaps the distribution in IL28B gene polymorphisms). Whatever the reasons, most patients with EVR in HEPAIG had RVR previously. Only two patients in HEPAIG experienced EVR but not RVR. Although both of these patients achieved SVR, this finding is not sufficient to draw conclusions, in contrast with the ATAHC study, where 17/20 patients with EVR but not RVR experienced SVR. ${ }^{2}$ Whether the three patients who did not experience SVR would have benefited from a longer course cannot be established from the ATAHC study.

Recent cohort studies on acute hepatitis C in HIV-infected patients are quite supportive and complementary in helping to define the best strategy in treating acute hepatitis $\mathrm{C}$ in HIVinfected patients. They highlight the pivotal role of HCV kinetics assessment on the management of HCV therapy. From both the HEPAIG $^{1}$ and ATAHC reports, ${ }^{2,3}$ patients with RVR have to be treated for 24 weeks. For patients experiencing EVR but not RVR, SVR rate following a 24-week course ranges from $75 \%$ in the European Cohort Study ${ }^{4}$ (albeit including some patients with a 48week course therapy) to $85 \%$ in ATAHC, ${ }^{2}$ compared with a hepatitis C virus (HCV) eradication rate of $100 \%(10 / 10)$ with a longer course in HEPAIG. ${ }^{1}$ Whether this mean difference of roughly $15 \%-20 \%$ is significant, relevant, or marginal may be debated and should only be addressed in randomized, controlled trials. Nevertheless, our conclusions parallel the recent recommendations of the NEAT consensus conference stating that it would be reasonable to aim for a 24-week course, with a longer duration reserved for those without RVR but with EVR. ${ }^{5}$ Finally, we also agree that new HCV therapies will probably lead to modifications in these propositions, not only by improving the success rate of retreatment of patients failing to respond to first line pegylated interferon-ribavirin therapy, but also as a first-line treatment of acute hepatitis C.
LiOnel Piroth $^{1}$
Christine LARSEN $^{2}$
Elisabeth DelarocQue-Astagneau ${ }^{2,3}$
STANISLAS POL ${ }^{4}$
On behalf of the steering committee of the HEPAIG study
${ }^{I}$ Infectious Diseases Department, University Hospital, and Université de Bourgogne, Dijon, France
${ }^{2}$ Institut de Veille Sanitaire, Saint Maurice, France 
${ }^{3}$ Unité d'épidémiologie des maladies émergentes, Institut Pasteur, Paris, France

${ }^{4}$ Université Paris Descartes, Institut Cochin Inserm U1016 and service d'Hépatologie, APHP-Hôpital Cochin, Paris, France

\section{References}

1. Piroth L, Larsen C, Binquet C, Alric L, Auperin I, Chaix ML, et al. Treatment of acute hepatitis $\mathrm{C}$ in human immunodeficiency virusinfected patients: the HEPAIG study. Hepatology 2010;52:1915-1921.

2. Dore GJ, Hellard M, Matthews GV, Grebely J, Haber PS, Petoumenos $\mathrm{K}$, et al. Effective treatment of injecting drug users with recently acquired hepatitis C virus infection. Gastroenterology 2010;138: 123-135.

3. Matthews GV, Hellard M, Haber P, Yeung B, Marks P, Baker D, et al. Characteristics and treatment outcomes among HIV-infected individuals in the Australian Trial in Acute Hepatitis C. Clin Infect Dis 2009;48: 650-658.

4. Vogel M, Dominguez S, Bhagani S, Azwa A, Page E, Guiguet M, et al. Treatment of acute HCV infection in HIV-positive patients: experience from a multicentre European cohort. Antivir Ther 2010;15: 267-279.

5. The European AIDS Treatment Network (NEAT) Acute Hepatitis C Infection Consensus Panel.Acute hepatitis C in HIV-infected individuals: recommendations from the European AIDS Treatment Network (NEAT) Consensus Conference. AIDS 2010; doi:10.1097/ QAD.0b013e328343443b.

Copyright $(2010$ by the American Association for the Study of Liver Diseases. View this article at wileyonlinelibrary.com. DOI 10.1002/hep.24181

Potential conflict of interest: Nothing to report.

\section{The Wide Spectrum of Hepatic Iron Overload}

To the Editor:

We read with great interest the article by Nelson et al. ${ }^{1}$ The authors elegantly described the association between patterns of intrahepatic iron deposition (within the hepatocytes [HC]; in the reticular endothelial cells [RES]; or both, HC/RES), liver histology, and metabolic abnormalities, including dyslipidemia and insulin resistance in the large cohort of adult patients from the NonAlcoholic Steatohepatitis Clinical Research Network (NASHCNR). Intrahepatic iron deposition was found in $34.5 \%$ of patients. Most of them (44.7\%) showed a mixed pattern, while the RES pattern was significantly associated with more severe histological damage and, particularly, with fibrosis. ${ }^{1}$ These findings seem to support the concept that differences may exist in patients with fatty liver based on different genetic background, inclination to inflammation, and co-occurrence of metabolic abnormalities such as diabetes. In this context, hepatic iron overload would represent a complex phenotype resulting from the maladaptation to environmental cues, mainly nutrients, and nurtured by metabolic abnormalities such as altered glucose metabolism (Fig. 1). ${ }^{2}$

$\mathrm{C} 282 \mathrm{Y}$ homozygous individuals were excluded from the NASH-CNR survey, as, by far, this mutation is the commonest form of hereditary hemochromatosis. Nevertheless, it should be useful to know how many individuals in the cohort carry any HFE and non-HFE mutation among those causing iron overload syndrome. ${ }^{2}$ By categorizing patients according to their genetic background and/or prevalence of metabolic disorders (mainly diabetes), probably a more clear overview of the complex picture of the iron overload syndrome would emerge.
Moreover, information on the genetic background would also be informative for explaining the difference in pattern of iron staining observed in this cohort respect with European series. ${ }^{1,3}$ In this regard, differences may also involve children with fatty liver. Different from the low prevalence of hepatic siderosis observed in patients younger than 18 years by the authors, in our series of 66 youths of European ancestry with fatty liver we observed low to mild intrahepatic iron deposition in 15 patients (23\%). Two of them showed an RES pattern, five an HC pattern and eight patients had a mixed pattern of iron deposition. ${ }^{4}$ Accordingly, the prevalence of positive iron staining in youth, even though of lowmedium grade, seems to be not as negligible as observed from the authors in their cohort.

The last concern is for the presence of diabetic patients in this cohort. Diabetes entered regression models as a covariate, but it should be of interest to know how many diabetic patients had hepatic siderosis and what was their prevalent pattern of iron deposition. Indeed, diabetes might represent a different pathogenic category in the heterogeneous sets of iron overload syndromes.

Categorizations of patients with fatty liver and iron overload syndrome may be particularly important, in terms of therapeutic procedures, to discriminate patients who can benefit from blood letting, which has been demonstrated to be useful in most of these syndromes. $^{5-7}$

We congratulate the authors on their excellent work; however, by adding the above information important insights may be provided.
Fig. 1. Interactions between HFE and nonHFE gene with environmental cues (nutrients and poor physical activity) and metabolic abnormalities (i.e., altered glucose metabolism) leading to intrahepatic iron accumulation.

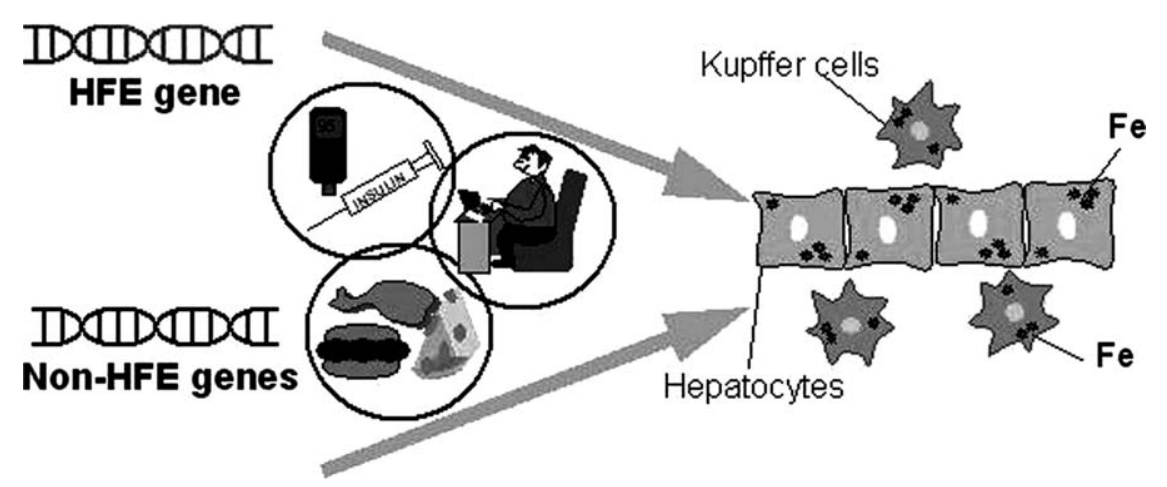


Melania Manco, M.D., Ph.D., F.A.C.N.

Anna Alisi, Ph.D.

Antonella Mosca, M.D.

VAlerio Nobili, M.D.

Laboratorio di Malattie Epatiche Auto-Immuni e Metaboliche Ospedale Pediatrico Bambino Gesu IRCCS, Centro di Nutrizione e Dietetica Dipartimento di Pediatria Università La Sapienza Roma, Italia

\section{References}

1. Nelson JE, Wilson L, Brunt EM, Yeh MM, Kleiner DE, Unalp-Arida A, et al. Relationship between the pattern of hepatic iron deposition and histological severity in nonalcoholic fatty liver disease. Hepatology 2010 Oct 11 [Epub ahead of print].

2. Pietrangelo A.Hereditary hemochromatosis: pathogenesis, diagnosis, and treatment. Gastroenterology 2010;139:393-408.

3. Valenti L, Fracanzani AL, Bugianesi E, Dongiovanni P, Galmozzi E, Vanni E, et al. HFE genotype, parenchimal iron accumulation, and liver fibrosis in patients with non-alcoholic fatty liver disease. Gastroenterology 2010;138:905-912.

4. Manco M, Alisi A, Fernandez Real JM, Equitani F, DeVito R, Valenti L, et al. Early interplay of intra-hepatic iron and insulin resistance in children with non-alcoholic fatty liver disease. J Hepatol 2010 [Epub ahead of print].

5. Equitani F, Fernandez-Real JM, Menichella G, Koch M, Calvani M, Nobili V, et al. Bloodletting ameliorates insulin sensitivity and secretion in parallel to reducing liver iron in carriers of HFE gene mutations. Diabetes Care 2008;31:3-8.

6. Fernández-Real JM, Peñarroja G, Castro A, García-Bragado F, HernándezAguado I, Ricart W.Blood letting in high-ferritin type 2 diabetes: effects on insulin sensitivity and beta-cell function. Diabetes 2002;51:1000-1004.

7. Valenti L, Fracanzani AL, Dongiovanni P, Bugianesi E, Marchesini G, Manzini $\mathrm{P}$, et al. Iron depletion by phlebotomy improves insulin resistance in patients with non-alcoholic fatty liver disease and hyperferritinemia: evidence from a case-control study. Am J Gastroenterol 2007;102:1251-1258.

Copyright $(92010$ by the American Association for the Study of Liver Diseases. View this article at wileyonlinelibrary.com.

DOI 10.1002/hep.24142

Potential conflict of interest: Nothing to report.

\section{Reply}

We would like to thank Manco and colleagues for their interest in our article. ${ }^{1}$ We agree that stratification of our study cohort according the presence of diabetes and HFE (hereditary hemochromatosis) genotype status could be of interest. We have conducted additional analyses with regard to diabetes status in our cohort. $H F E$ genotyping was not routinely performed as part of the Nonalcoholic Steatohepatitis Clinical Research Network (NASH CRN) Database study; this is currently in progress in an ancillary study. Among the 849 adult subjects in our study, 221 were enrolled in the PIVENS (Pioglitazone or Vitamin E for NASH Study) clinical trial, ${ }^{2}$ which excluded diabetic patients; therefore, to prevent any potential bias, we report here the relationship of diabetes and iron deposition in the remaining 628 subjects.

As shown in Table 1, diabetic NASH CRN subjects were less likely to have hepatic iron deposition. In particular, diabetic patients had significantly less hepatocellular but not reticuloendothelial system iron deposition. There are several possible explanations for these findings. The iron regulatory hormone hepcidin is expressed in adipose tissue and has been shown to correlate to body mass index. ${ }^{3}$ It is possible that increased visceral fat in our diabetic subjects could lead to greater circulating hepcidin levels,
Table 1. Iron Stain Status of 628 NASH CRN Database Study Subjects

\begin{tabular}{|c|c|c|c|}
\hline & $\begin{array}{l}\text { No diabetes } \\
(\mathrm{N}=394)\end{array}$ & $\begin{array}{l}\text { Diabetes } \\
(\mathrm{N}=\mathbf{2 3 4})\end{array}$ & $P$ Value* \\
\hline \multicolumn{4}{|l|}{ Iron stain status } \\
\hline Any iron present & $146(37)$ & $68(29)$ & 0.041 \\
\hline $\mathrm{HC}$ iron present & $109(28)$ & $42(18)$ & 0.006 \\
\hline RES iron present & $110(28)$ & $56(24)$ & 0.273 \\
\hline HC iron only & $36(9)$ & $12(5)$ & 0.068 \\
\hline RES iron only & $37(9)$ & $26(11)$ & 0.488 \\
\hline Mixed HC/RES iron present & $73(18)$ & $30(13)$ & 0.062 \\
\hline \multicolumn{4}{|c|}{ Potential factors influencing iron staining } \\
\hline Body mass index $\left(\mathrm{kg} / \mathrm{m}^{2}\right)$ & $33.6 \pm 6.2$ & $35.6 \pm 6.0$ & $<0.0001$ \\
\hline Female sex & $244(62)$ & $167(71)$ & 0.016 \\
\hline Any alcohol consumption & $205(52)$ & $75(32)$ & $<0.001$ \\
\hline $\begin{array}{l}\text { Alcohol consumption } \\
\text { (>2 drinks/week) }\end{array}$ & $26(7)$ & $2(1)$ & $<0.001$ \\
\hline $\begin{array}{l}\text { Alcohol consumption } \\
\text { (drinks/drinking day) }\end{array}$ & $0.18 \pm 0.47$ & $0.08 \pm 0.36$ & 0.045 \\
\hline $\begin{array}{l}\text { History of any } \\
\text { gastrointestinal bleeding }\end{array}$ & $31(8)$ & $27(12)$ & 0.125 \\
\hline $\begin{array}{l}\text { Dietary iron consumption } \\
(\mathrm{mg} / \text { day })\end{array}$ & $13.9 \pm 7.3$ & $12.9 \pm 6.6$ & 0.105 \\
\hline $\begin{array}{l}\text { Dietary vitamin } \mathrm{C} \\
\text { consumption (mg/day) }\end{array}$ & $109 \pm 75$ & $96 \pm 66$ & 0.007 \\
\hline
\end{tabular}

Values are $\mathrm{N}(\%)$ or mean \pm standard deviation.

* $P$ values from chi-square, Fisher's exact test orWilcoxon rank sum test. Abbreviations: HC, hepatocellular; RES, reticuloendothelial system.

reduced iron absorption, and less hepatocellular iron deposition. Recently, alcohol has been shown to down-regulate hepcidin gene expression. ${ }^{4}$ Because diabetic subjects in our study consumed less alcohol than subjects without diabetes, this could also contribute to higher hepcidin levels in these patients. Diabetic subjects were also more likely to be women, and physiologic blood loss through menstruation and childbirth may have resulted in decreased body iron stores. Additional studies are warranted to define the mechanism for decreased hepatocellular iron content in diabetic patients with NAFLD.

In contrast to Manco et al., ${ }^{5}$ who have reported hepatic iron deposition in $29 \%$ of their Italian pediatric subjects, which was not associated with measurements of insulin resistance, the prevalence of iron deposition in the NASH CRN pediatric subjects was only $4 \%$. It is likely that, as in adults, differences in the Italian and U.S. cohorts, including body mass index (25.2 in Manco et al. versus 33.0 in the NASH CRN pediatric subjects) account for the observed differences. ${ }^{6}$

\author{
James Nelson, Ph.D. \\ KRIS KOWDLEY, M.D. \\ Benaroya Research Institute \\ Virginia Mason Medical Center \\ Seattle, WA
}

\section{References}

1. Nelson JE, Wilson L, Brunt EM, Yeh MM, Kleiner DE, Unalp-Arida A, et al. Relationship between the pattern of hepatic iron deposition and histological severity in nonalcoholic fatty liver disease. Hepatology 2010; doi:10.1002/hep.24038.

2. Sanyal AJ, Chalasani N, Kowdley KV, McCullough A, Diehl AM, Bass NM, et al.; NASH CRN.Pioglitazone, vitamin E, or placebo for nonalcoholic steatohepatitis. N Engl J Med 2010;362:1675-1685.

3. Bekri S, Gual P, Anty R, Luciani N, Dahman M, Ramesh B, et al. Increased adipose tissue expression of hepcidin in severe obesity is 
independent from diabetes and NASH. Gastroenterology 2006;131: 788-796.

4. Harrison-Findik DD, Schafer D, Klein E, Timchenko NA, Kulaksiz $\mathrm{H}$, Clemens D, et al. Alcohol metabolism-mediated oxidative stress down-regulates hepcidin transcription and leads to increased duodenal iron transporter expression. J Biol Chem 2006;281:2297422982.

5. Manco M, Alisi A, Fernandez Real JM, Equitani F, DeVito R, Valenti L, et al. Early interplay of intra-hepatic iron and insulin resistance in children with non-alcoholic fatty liver disease. J Hepatol 2010; doi: 10.1016/j.jhep.2010.12.007.

6. Kowdley KV. The role of iron in nonalcoholic fatty liver disease: the story continues. Gastroenterology 2010;138:817-819.

Copyright $@ 2010$ by the American Association for the Study of Liver Diseases. View this article at wileyonlinelibrary.com.

DOI 10.1002/hep.24184

Potential conflict of interest: Nothing to report.

\section{Treatment of Hepatic Encephalopathy with Rifaximin: More to Think About}

\section{To the Editor:}

The recent publication of "Drug Therapy: Rifaximin" by Bajaj and Riggio ${ }^{1}$ offers interesting observations by colleagues. They voice concern that continuous rifaximin administration "could have the potential to increase resistance to rifaximin," but they cite no objective clinical data in support of their hypothesis. They also cite the two cases of Clostridium difficile in the rifaximin group reported in the registration study of rifaximin for the treatment of hepatic encephalopathy by Bass and colleagues, ${ }^{2}$ and they advise vigilance against $C$. difficile in patients with cirrhosis treated with rifaximin. At the US Food and Drug Administration meeting in March 2010, this matter was extensively studied and discussed. Both patients who developed $C$. difficile had concurrently received other antimicrobials known to cause $C$. difficile infection. Bajaj and Riggio's suggestion of pulse therapy with rifaximin (to reduce costs) is without precedent or merit in the realm of antimicrobial therapy. Their statement regarding rifaximin that "the current role appears to be a second-line [therapy]" is again without scientific merit. Lactulose is an effective therapy for hepatic encephalopathy; however, its use and patient compliance are severely limited and restricted by its well-recognized adverse event profile of nausea, vomiting, bloating, diarrhea, and incontinence. Rifaximin is very well tolerated, and it not only improves the duration of remission of hepatic encephalopathy but also lessens the need for repeated hospitalization. ${ }^{2}$ Both factors require consideration when one is calculating the overall cost of the two agents, their beneficial effects, and patient preference, compliance, and quality of life.

\section{Norman Gituin, M.D. \\ Atlanta Gastroenterology Associates Atlanta, GA}

\section{References}

1. Bajaj JS, Riggio O. Drug therapy: rifaximin. Hepatology 2010;52: 1484-1488.

2. Bass NM, Mullen KD, Sanyal A, Poordad F, Neff G, Leevy CB, et al. Rifaximin treatment in hepatic encephalopathy. N Engl J Med 2010; 362:1071-1081.

Copyright $(2010$ by the American Association for the Study of Liver Diseases. View this article at wileyonlinelibrary.com. DOI 10.1002/hep.24112

Potential conflict of interest: Dr. Gitlin is on the speakers' bureau of Salix.

\section{Reply}

We read with interest the letter by Gitlin, which raises several important points pertaining to the use of rifaximin for hepatic encephalopathy (HE). Long-term use of any antibiotic does carry the risk of resistance; however, the low likelihood of this appearing with rifaximin due to the nonplasmid nature of its resistance was also cited in the article. ${ }^{1}$ The U.S. Food and Drug Administration (FDA) approval for rifaximin, granted as a result of the same March 2010 meeting that is mentioned in the letter, comes along with the warning, as with all antibiotics, for the continuous monitoring of patients on this therapy for Clostridium difficile. ${ }^{2}$

The article referred to the differences in the use of rifaximin across countries, cyclical therapy in Italy, and continuous therapy that is being currently used in the United States and presents possible advantages and disadvantages of both approaches. The precedence and scientific merit of this therapy is evident in the publications and the clinical practice in Italy regarding the use of rifaximin, which was referenced in the article. ${ }^{3,4}$ Although the points about the adverse events of lactulose as pointed out in the letter are noted and it is also known from clinical experience that rifaximin is well tolerated in patients, prospective evidence using a large-scale, head-to-head comparison of rifaximin compared to lactulose is still awaited. ${ }^{5,6}$ Bass et al. indeed demonstrated that administration of rifaximin with lactulose prevented hospitalizations and $\mathrm{HE}$ recurrences compared to administration of lactulose alone in patients who had two prior HE episodes, but this needs further evaluation in patients who have had their first HE episode. ${ }^{7}$ There is also a huge cost difference between rifaximin and lactulose and the evidence that rifaximin reduces overall costs and hospitalizations outside the selected population in the trial by Bass et al. is from retrospective, single-center studies. ${ }^{1,8,9}$ Therefore, to answer these important questions, the FDA has mandated postmarketing trials comparing lactulose and rifaximin for $\mathrm{HE}$ and to study rifaximin in patients who have a Model for End-Stage Liver Disease score $\geq 19 .{ }^{10}$ Until these trials are completed, from an evidencebased medicine approach, we stand by the recommendations in the article regarding the role of rifaximin

Jasmohan S. Bajaj, M.D. ${ }^{1}$

Oliviero RigGio, M.D. ${ }^{2}$

${ }^{1}$ Division of Gastroenterology, Hepatology and Nutrition, Virginia Commonwealth University and McGuire Veterans Administration Medical Center, Richmond, VA

${ }^{2}$ Department of Clinical Medicine, Center for the Diagnosis and Treatment of Portal Hypertension, Sapienza University of Rome Rome, Italy

\section{References}

1. Bajaj JS, Riggio O. Drug therapy: rifaximin. Hepatology 2010;52: 1484-1488.

2. Xifaxan prescribing information. http://www.accessdata.fda.gov/ drugsatfda_docs/label/2010/022554lbl.pdf. Accessed January 2011. 
3. Alcorn J. Review: rifaximin is equally or more effective than other antibiotics and lactulose for hepatic encephalopathy. ACP J Club 2008;149:11.

4. Loguercio C, Federico A, De Girolamo V, Ferrieri A, Del Vecchio Blanco C. Cyclic treatment of chronic hepatic encephalopathy with rifaximin. Results of a double-blind clinical study. Minerva Gastroenterol Dietol 2003;49:53-62.

5. Bajaj JS, Sanyal AJ, Bell D, Gilles H, Heuman DM. Predictors of the recurrence of hepatic encephalopathy in lactulose-treated patients. Aliment Pharmacol Ther 2010;31:1012-1017.

6. Kalaitzakis E, Bjornsson E. Lactulose treatment for hepatic encephalopathy, gastrointestinal symptoms, and health-related quality of life. HEPATOLOGY 2007;46:949-950.

7. Bass NM, Mullen KD, Sanyal A, Poordad F, Neff G, Leevy CB, et al. Rifaximin treatment in hepatic encephalopathy. N Engl J Med;362: 1071-1081.
8. Neff GW, Kemmer N, Zacharias VC, Kaiser T, Duncan C, McHenry R, et al. Analysis of hospitalizations comparing rifaximin versus lactulose in the management of hepatic encephalopathy. Transplant Proc 2006;38:3552-3555.

9. Leevy $\mathrm{CB}$, Phillips JA. Hospitalizations during the use of rifaximin versus lactulose for the treatment of hepatic encephalopathy. Dig Dis Sci 2007; $52: 737-741$.

10. New Drug Approval Letter for Xifaxan. http://www.accessdata.fda.gov/ drugsatfda_docs/appletter/2010/022554s000ltr.pdf. Accessed January 2011.

Copyright $(2010$ by the American Association for the Study of Liver Diseases. View this article at wileyonlinelibrary.com. DOI 10.1002/hep.24187

Potential conflict of interest: Dr. Bajaj advises, consults for, and received grants from Salix.

\section{Alpha-Fetoprotein Should Be Included in the Hepatocellular Carcinoma Surveillance Guidelines of the American Association for the Study of Liver Diseases}

\section{To the Editor:}

We read with interest the updated hepatocellular carcinoma (HCC) guidelines by the American Association for the Study of Liver Diseases. ${ }^{1}$ We were surprised by the omission of alpha-fetoprotein (AFP) testing in the recommendations for HCC surveillance. We disagree with these recommendations.

In making recommendations, the writers of practice guidelines should consider the quality of the evidence. The HCC guidelines ignore a significant amount of data about the use of AFP in the surveillance of patients at risk for HCC. The only available level 1 evidence for HCC surveillance comes from one randomized controlled trial of ultrasonography (US) combined with AFP testing every 6 months in a hepatitis $\mathrm{B}$ carrier population. ${ }^{2}$ The next best available evidence comes from a population-based cohort surveillance program involving hepatitis B carriers in Alaska that showed improved outcomes. ${ }^{3}$ The remainder of the literature includes population-based and non-population-based cohorts and case-control studies open to multiple sources of bias. ${ }^{4,5}$ Although it may be reasonable to generalize the findings of the available randomized trial and population-based study to other patient groups with cirrhosis or hepatitis C, we feel that it is inappropriate to drop one of the interventions (i.e., AFP) found to work.

The guidelines cite the Hepatitis C Antiviral Long-Term Treatment Against Cirrhosis (HALT-C) study as the main source for the lack of efficacy of AFP in patients with cirrhosis. ${ }^{6}$ There are significant limitations to this study. First, only $40 \%$ of the patients had cirrhosis. Second, HCC surveillance was not the primary purpose of HALT-C. Third, AFP had a sensitivity and specificity at the time of HCC diagnosis of $61 \%$ and $81 \%$, respectively, whereas US had a sensitivity of only $58 \%$, which is inadequate according to the criteria stated in the guidelines. Interestingly, $40 \%$ of the patients with early-stage HCC were diagnosed by an increasing AFP level alone or in combination with US. Therefore, AFP appears to complement US for the surveillance of HCC.

In addition to ignoring the highest level of evidence for the efficacy of US combined with AFP in research studies, the HCC guidelines also neglect the effectiveness of the tests in clinical practice. Test reproducibility, a major determinant of translating the results of research studies into practice, has never been evaluated for US as an HCC surveillance test. Another issue is underutilization of surveillance tests. In the only population-based study evaluating surveillance for HCC, only $17 \%$ of patients with HCC underwent regular surveillance before their diagnosis. ${ }^{7}$ Dropping AFP from the guidelines may potentially lower the percentage of patients undergoing surveillance.
Surveillance for HCC has a whole host of confounding factors that make it impossible to detect benefit through personal experiences and clinical observations alone. ${ }^{8}$ Therefore, randomized controlled studies are the only reliable way of evaluating surveillance and changing clinical practice. In the absence of randomized studies in patients with cirrhosis, the current evidence points to US combined with serum AFP as the most effective surveillance strategy for patients at risk for HCC. The guidelines should be revised to recommend US with $\mathrm{AFP}$ as the best available surveillance strategy.

\author{
Jorge A. Marrero, M.D., M.S. ${ }^{1}$ \\ Hashem B. El-Serag, M.D., M.P.H. ${ }^{2}$ \\ ${ }^{1}$ Division of Gastroenterology, University of Michigan \\ Ann Arbor, MI \\ ${ }^{2}$ Michael E DeBakey VA Medical Center \\ Baylor College of Medicine, Houston, TX
}

\section{References}

1. Bruix J, Sherman M. Management of hepatocellular carcinoma. Hepatology 2010;52.

2. Zhang BH, Yang BH, Tang ZY. Randomized controlled trial of screening for hepatocellular carcinoma. J Cancer Res Clin Oncol 2004;130:417-422.

3. McMahon BJ, Bulkow L, Harpster A, Snowball M, Lanier A, Sacco F, et al. Screening for hepatocellular carcinoma in Alaska natives infected with chronic hepatitis B: a 16-year population-based study. HepATOLOGY 2000;32(pt 1):842-846.

4. Thompson Coon J, Rogers G, Hewson P, Wright D, Anderson R, Cramp $\mathrm{M}$, et al. Surveillance of cirrhosis for hepatocellular carcinoma: a systematic review and economic analysis. Health Technol Assess 2007;11:1-206.

5. Singal A, Volk ML, Waljee A, Salgia R, Higgins P, Rogers MA, et al. Metaanalysis: surveillance with ultrasound for early-stage hepatocellular carcinoma in patients with cirrhosis. Aliment Pharmacol Ther 2009;30:37-47.

6. Lok AS, Sterling RK, Everhart JE, Wright EC, Hoefs JC, Di Bisceglie AM, et al. Des-gamma-carboxy prothrombin and alpha-fetoprotein for the early detection of hepatocellular carcinoma. Gastroenterology 2010;138:493-502.

7. Davila JA, Morgan RO, Richardson PA, Du XL, McGlynn KA, El-Serag HB. Use of surveillance for hepatocellular carcinoma among patients with cirrhosis in the United States. Hepatology 2010;52:132-141.

8. Brawley OW, Kramer BS. Cancer screening in theory and in practice. J Clin Oncol 2005;23:293-300.

Copyright $(\odot 2010$ by the American Association for the Study of Liver Diseases. View this article at wileyonlinelibrary.com.

DOI 10.1002/hep.24033

Potential conflict of interest: Nothing to report. 


\section{Reply:}

We thank Drs. Marrero and El-Serag ${ }^{1}$ for their comments on the recently published guidelines on the management of hepatocellular carcinoma (HCC). ${ }^{2}$ The use of alpha-fetoprotein (AFP) as a screening test for HCC has long been controversial, although it should not be so. The evidence is clear that AFP is a poor screening test.

In response to Drs. Marrero and El-Serag, ${ }^{1}$ we offer the following comments:

We agree that a randomized controlled trial is the best evidence of the efficacy of screening, and the only such trial is that published from China in 2004. ${ }^{3}$ The study compared screening with AFP and ultrasound (US) to no screening and demonstrated a $37 \%$ decrease in mortality in the screened group. This outcome could have been due to AFP alone, to ultrasonography alone, or to both. Drs. Marrero and El Serag have assumed that both AFP and US are necessary. However, a separate analysis of data from the same study indicated that adding AFP to US did increase the detection rate slightly, but also increased the false-positive rate and more than doubled the cost per tumor found compared to US alone. ${ }^{4}$ Other support comes from cost efficacy analyses. Of the several that have been published so far, the one that most closely mimics our current approach to HCC is that of Andersson et al., which shows that screening with US is cost-effective, but when AFP is added there is little benefit and considerable increased cost. A separate analysis ${ }^{6}$ suggested that the most cost-effective method of screening was with AFP alone, but adding US increased efficacy although it also increased cost. Some of the assumptions about the sensitivity and specificity of AFP in this analysis was suspect, so the AFP analysis must be taken with a grain of salt. Thus, these studies would lead one to conclude that adding AFP to US does not add much.

Furthermore, there are many studies that have examined the efficacy of AFP as a diagnostic test, ${ }^{7-10}$ but few that have evaluated AFP as a screening test. ${ }^{11,12}$ Results from these studies are completely discordant, with one showing that AFP as the sole screening test is effective in identifying treatable cancers ${ }^{12}$ and the other suggesting the opposite. ${ }^{11}$ In general, as expected, those studies in which AFP is used as a diagnostic test show a better performance. For example, Trevisani et al. 7 showed that as a diagnostic test, the positive predictive value of AFP in a population where $50 \%$ of the cases had HCC, and at a cutoff of $20 \mathrm{ng} / \mathrm{mL}$, was $85 \%$. However, if the prevalence of HCC was reduced to $5 \%$ (still much too high for a screening population), the PPV was only $25 \%$. Even if the cutoff was raised to $400 \mathrm{ng} / \mathrm{mL}$, the PPV was only $60 \%$ at HCC prevalence of $5 \%$. Dr. Marrero undertook a similar study recently, ${ }^{8}$ and demonstrated that the sensitivity of AFP at a cutoff of about $11 \mathrm{ng} / \mathrm{mL}$ overall was only 66\%. In early stage disease (defined essentially as the Milan transplant criteria, or BCLC stage A), the sensitivity was only $53 \%$ at an AFP cutoff of $20 \mathrm{ng} / \mathrm{mL}$. It is a question of whether the glass is half full or half empty. To Dr. Marrero and his colleagues, this is adequately sensitive as a screening test, but to us, it is not. We do not believe that identification of lesions of $5 \mathrm{~cm}$ or multiple lesions should be the target size for a screen-detected lesion. The cure rate (apart from transplantation) is less than optimal for this size of lesion. A $5-\mathrm{cm}$ tumor falls within criteria for transplantation, which has a high cure rate, but the proportion of all patients with HCC who get a transplant is very small, ${ }^{13}$ and is unlikely to have any effect on overall mortality. (Reduction in mortality is ultimately the goal of screening, and tests that do not reduce mortality in the screened population are useless). AFP is not sensitive enough to identify the majority of these small HCCs. US, in contrast, does have adequate sensitivity, at least in Europe, Japan, and Canada, where the majority of HCCs identified in patients undergoing screening are smaller than $3 \mathrm{~cm}$. Even in the United States, a meta-analysis in which Dr. Marrero participated showed that US was more sensitive than AFP, the HALT-C (Hepatitis C Antiviral Long-Term Treatment Against Cirrhosis) study results notwithstanding. ${ }^{.}{ }^{4}$
There seem to be two reasons why AFP testing remains popular. One is an inadequate appreciation of the appropriate target lesion size as discussed above, and the second, we think, is that AFP is a marker of increased HCC risk. Therefore, it is not surprising that HCC is found more often in patients with an elevated AFP than in those with normal AFP. However, this does not make AFP a good screening test. The false-positive rate of AFP testing is high, but there is little data on the costs and harms of investigating these false-positives. Furthermore, there is ample evidence that AFP is a marker of poor prognosis. Screening should identify good prognosis lesions. Finding poor prognosis lesions is unlikely to improve overall survival.

Drs. Marrero and El Serag imply that effectiveness (as opposed to efficacy) of screening may be reduced because of the need for regular US that might reduce the frequency of screening. This is a theoretical concern, but the alternative would be not to perform US and only to use AFP. There is no data to support this practice. No guideline suggests using only AFP. Given all the negative data, to recommend that AFP be used as the single screening test is, in our view, unsupportable.

Thus, although the randomized controlled study of HCC screening used both AFP and US, we believe that contribution of AFP to the outcome was minimal, and maintain our position that it should not be used. US is a better test, and we should not be recommending inferior tests in guidelines such as this.

$$
\begin{aligned}
& \text { Morris Sherman, M.D. }{ }^{1} \\
& \text { Jordi Bruix, M.D. }{ }^{2} \\
& { }^{1} \text { Toronto General Hospital, Toronto, Canada } \\
& { }^{2} \text { Liver Unit, BCLC Hospital Clinic, Barcelona, Spain }
\end{aligned}
$$

\section{References}

1. Marrero J, El-Serag H. Alpha-fetoprotein should be included in the hepatocellular carcinoma surveillance guidelines of the American Association for the Study of Liver Diseases. Hepatology 2010; doi: 10.1002/hep. 24033.

2. Bruix J, Sherman M. Management of hepatocellular carcinoma: an update. Published July 2010. http://www.aasld.org/practiceguidelines/. Accessed February 2011.

3. Zhang BH, Yang BH, Tang ZY. Randomized controlled trial of screening for hepatocellular carcinoma. J Cancer Res Clin Oncol 2004;130:417-422.

4. Zhang B, Yang B. Combined alpha fetoprotein testing and ultrasonography as a screening test for primary liver cancer. J Med Screen 1999;6:108-110.

5. Andersson KL, Salomon JA, Goldie SJ, Chung RT. Cost effectiveness of alternative surveillance strategies for hepatocellular carcinoma in patients with cirrhosis. Clin Gastroenterol Hepatol 2008;6:1418-1424.

6. Thompson Coon J, Rogers G, Hewson P, Wright D, Anderson R, Jackson S, et al. Surveillance of cirrhosis for hepatocellular carcinoma: a cost-utility analysis. Br J Cancer 2008;98:1166-1175.

7. Trevisani F, D’Intino PE, Morselli-Labate AM, Mazzella G, Accogli E, Caraceni P, et al. Serum alpha-fetoprotein for diagnosis of hepatocellular carcinoma in patients with chronic liver disease: influence of HBsAg and anti-HCV status. J Hepatol 2001;34:570-575.

8. Marrero JA, Feng Z, Wang Y, Nguyen MH, Befeler AS, Roberts LR, et al. Alpha-fetoprotein, des-gamma carboxyprothrombin, and lectinbound alpha-fetoprotein in early hepatocellular carcinoma. Gastroenterology 2009;137:110-118.

9. Durazo FA, Blatt LM, Corey WG, Lin JH, Han S, Saab S, et al. Desgamma-carboxyprothrombin, alpha-fetoprotein and AFP-L3 in patients with chronic hepatitis, cirrhosis and hepatocellular carcinoma. J Gastroenterol Hepatol 2008;23:1541-1548.

10. Lok AS, Sterling RK, Everhart JE, Wright EC, Hoefs JC, Di Bisceglie AM, et al.; HALT-C Trial Group. Des-gamma-carboxy prothrombin and alpha-fetoprotein as biomarkers for the early detection of hepatocellular carcinoma. Gastroenterology 2010;138:493-502. 
11. Sherman M, Peltekian KM, Lee C. Screening for hepatocellular carcinoma in chronic carriers of hepatitis B virus: incidence and prevalence of hepatocellular carcinoma in a North American urban population. Hepatology 1995;22:432-438.

12. McMahon BJ, Bulkow L, Harpster A, Snowball M, Lanier A, Sacco F, et al. Screening for hepatocellular carcinoma in Alaska natives infected with chronic hepatitis B: a 16-year population-based study. Hepatology 2000;32(4 Pt 1):842-846

13. Stravitz RT, Heuman DM, Chand N, Sterling RK, Shiffman ML, Luketic VA, et al. Surveillance for hepatocellular carcinoma in patients with cirrhosis improves outcome. Am J Med 2008;121:119-126.
14. Singal A, Volk ML, Waljee A, Salgia R, Higgins P, Rogers MA, et al. Metaanalysis: surveillance with ultrasound for early-stage hepatocellular carcinoma in patients with cirrhosis. Aliment Pharmacol Ther 2009;30:37-47.

Copyright $($ C) 2010 by the American Association for the Study of Liver Diseases. View this article at wileyonlinelibrary.com.

DOI 10.1002/hep.24237

Potential conflict of interest: Dr. Bruix consults for Sunimoto, Pharmexa, Elsai, Biocompatibles, Angiodynamics, Kowa, and Imclong; advises for Bayer, Lilly, Novartis, Arqule, Schering Plough.

\section{Meta-Analysis Using Individual Participant Data Is the Gold Standard for Diagnostic Studies}

\section{To the Editor:}

We read the article by Lin et al. with great interest. ${ }^{1}$ Using aggregate data $(\mathrm{AD})$, the authors performed a meta-analysis to assess the accuracy of the aminotransferase-to-platelet ratio index in predicting fibrosis stage in hepatitis $\mathrm{C}$ virus (HCV)-monoinfected individuals and individuals coinfected with HCV and human immunodeficiency virus. However, we would like to comment on the concerns raised over their data collection approach.

As we know, AD usually refers to averaged or estimated data taken directly from reported literature; it is less accurate and can easily misinform readers. Therefore, individual participant data (IPD) is urgently needed. ${ }^{2}$ IPD meta-analysis (IPDMA) is widely considered to be more reliable than $\mathrm{AD}$ meta-analysis, and these two approaches may lead to wholly opposite conclusions. ${ }^{3,4}$ Currently, the number of published articles using IPDMA has risen dramatically from a few articles per year in the early 1990s to an average of 50 per year since 2005 (Fig. 1).

In contrast to $\mathrm{AD}$ meta-analysis on diagnostic studies, IPDMA has the potential to establish the value of test combinations. ${ }^{2,5,6}$ First, IPD can be considered as original continuous data rather than dichotomous classification data and can be analyzed from beginning to end. In addition, this approach is essential to determining a relation between test result and disease, because the test accuracy could be estimated at different cutoff values. Second, the

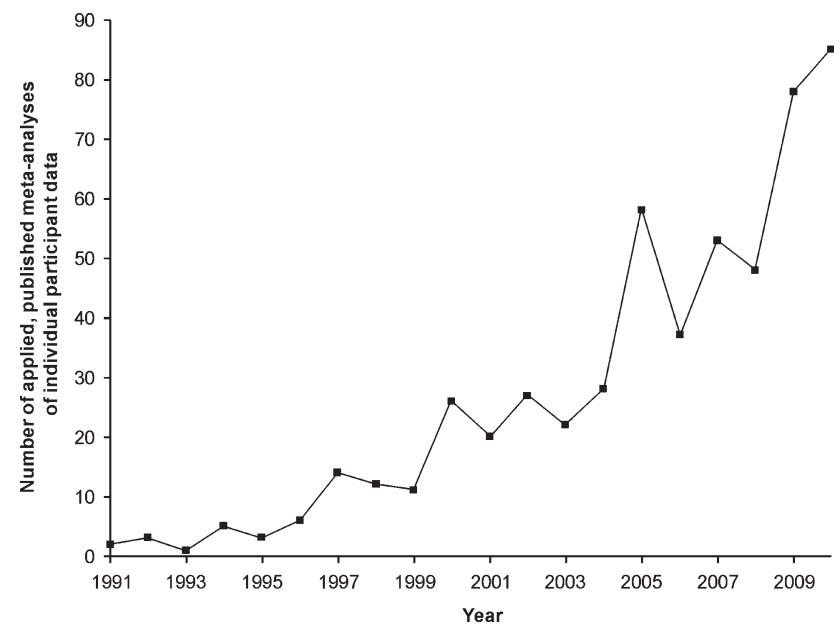

Fig. 1. Number of distinct, applied meta-analyses of individual participant data published from January 1991 to December 25, 2010, as identified by a systematic review of PubMed. association across patient-level characteristic or between patient level and study level characteristic (study design, setting) can be assessed, without the ecological fallacy problem.

In summary, IPDMA needs to be applied in the diagnostic study.

Ming-Hua Zheng, M.D. ${ }^{1}$

Ke-QIng Shi, M.D. ${ }^{1}$

Yu-CHEN FAN, M.D. ${ }^{2}$

YONG-PING CHEN, M.D. ${ }^{1}$

${ }^{1}$ Department of Infection and Liver Diseases, Liver Research Center The First Affiliated Hospital of Wenzhou Medical College Wenzhou, China

${ }^{2}$ Department of Hepatology, Qilu Hospital of Shandong University Jinan, China

\section{References}

1. Lin ZH, Xin YN, Dong QJ, Wang Q, Jiang XJ, Zhan SH, et al. Performance of the aspartate aminotransferase-to-platelet ratio index for the staging of hepatitis C-related fibrosis: An updated meta-analysis. HepATOLOGY 2010; doi: 10.1002/hep.24105.

2. Riley RD, Lambert PC, Abo-Zaid G. Meta-analysis of individual participant data: rationale, conduct, and reporting. BMJ 2010;340:c221.

3. Jeng GT, Scott JR, Burmeister LF. A comparison of meta-analytic results using literature vs individual patient data. Paternal cell immunization for recurrent miscarriage. JAMA 1995;274:830-836.

4. Oxman AD, Clarke MJ, Stewart LA. From science to practice. Meta-analyses using individual patient data are needed. JAMA 1995;274:845-846.

5. Cooper H, Patall EA. The relative benefits of meta-analysis conducted with individual participant data versus aggregated data. Psychol Methods 2009; 14:165-176.

6. Jones AP, Riley RD, Williamson PR, Whitehead A. Meta-analysis of individual patient data versus aggregate data from longitudinal clinical trials. Clin Trials 2009;6:16-27.

\section{Copyright $(2010$ by the American Association for the Study of Liver Diseases. View this article at wileyonlinelibrary.com. DOI 10.1002/hep. 24188 Potential conflict of interest: Nothing to report.}

Reply:

We highly appreciate the comments by Zheng et al. on the use of individual participant data (IPD) in diagnostic studies. We agree that meta-analysis using IPD from multiple clinical studies enables 
Fig. 1. Number of articles related "meta-analyses" published in PubMed from January 1991 to December 25, 2010 compared with number of distinct, applied IPDMA published from January 1991 to December 25, 2010, as identified by a systematic review of PubMed.

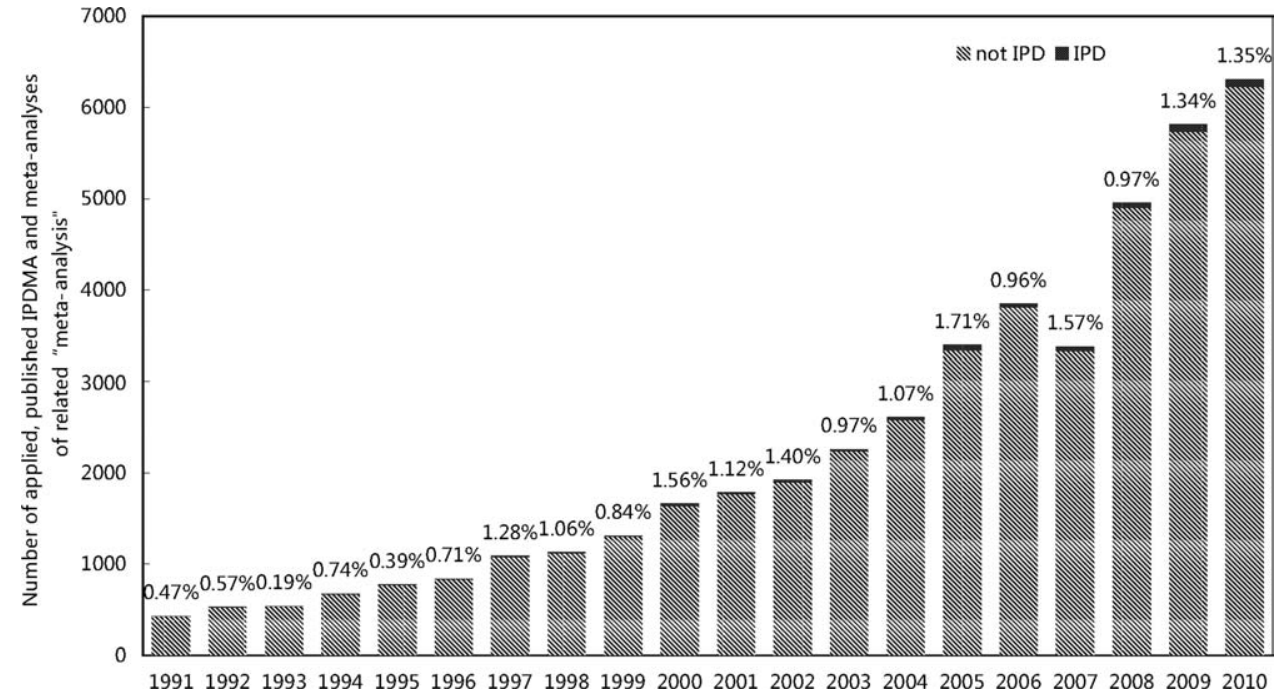

detailed investigation of diagnostic studies. We also found that increasing numbers of IPD meta-analyses (IPDMA) from observational data are being conducted to enhance the statistical power and detail of epidemiological studies, ${ }^{1}$ and this approach is being increasingly applied in many research studies. ${ }^{2}$ However, there is some skepticism as to whether IPDMA is really the gold standard for diagnostic studies, considering the fact that it involves a number of challenges. On this point, we have our own view.

First, in order to get a better comparison with the previous study conducted by Shaheen and Myers in $2007,{ }^{3}$ we used aggregate data (AD) instead of IPD to perform this updated metaanalysis.

Second, extra cost in effort, time, and complexity is required to obtain and manage raw data in IPDMA. Commendable examples of IPDMA are those conducted by the Emerging Risk Factors Collaboration (ERFC), ${ }^{4}$ who have remarkably collected IPD from 116 prospective studies and more than 1.2 million participants. Although meta-analysis methods using AD are well established and fairly routine, methods for IPDMA are more complex but less well known. Currently, although the number of published articles related to "meta-analysis" has risen dramatically from hundreds of articles per year in the early 1990s to thousands of articles every year since 2003, the number of articles of IPDMA only accounts for a negligible proportion of less than $1.71 \%$ (Fig. 1).

Finally, should one embark on an IPDMA when few studies provide their IPD, making it difficult to estimate random effects? Likewise, is an IPDMA reliable when only a proportion of existing studies provide IPD? Unfortunately this is the current situation that regrettably leads to what Riley ${ }^{5}$ referred to as availability bias - a human cognitive bias that tends to overestimate probabilities of events associated with memorable or vivid occurrences, where studies that provide IPD are a kind of biased subset of all existing studies.

In conclusion, we think that methods for IPDMA are prone to be affected by bias with inadequate generalizability despite their widely recognized strength. The appropriate strategy at this moment is probably to use both approaches in a complementary fashion, in which an $\mathrm{AD}$ meta-analysis is conducted in the first step rather than an IPDMA. As Riley pointed out, IPD is not the be-all and end-all for meta-analysis just yet. ${ }^{5}$

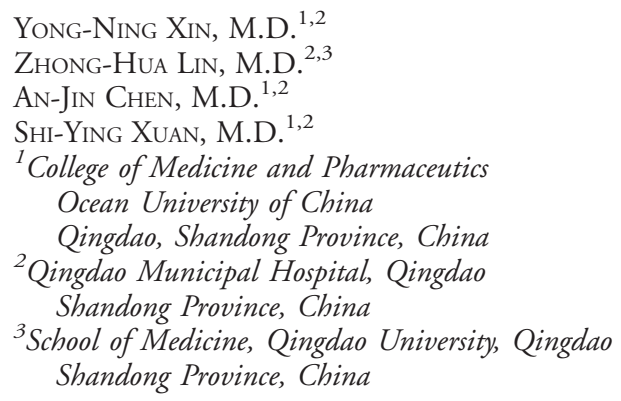

\section{References}

1. Thompson S, Kaptoge S, White I, Wood A, Perry P, Danesh J, et al. Statistical methods for the time-to-event analysis of individual participant data from multiple epidemiological studies. Int J Epidemiol 2010; 39:1345-1359.

2. Riley RD, Lambert PC, Abo-Zaid G. Meta-analysis of individual participant data: rationale, conduct, and reporting. BMJ 2010;340: c221.

3. Shaheen AA, Myers RP. Diagnostic accuracy of the aspartate aminotransferase-to-platelet ratio index for the prediction of hepatitis C-related fibrosis: a systematic review. Hepatology 2007;46:912-921.

4. Emerging Risk Factors Collaboration,Danesh J, Erqou S, Walker M, Thompson SG, Tipping R, et al. The Emerging Risk Factors Collaboration: analysis of individual data on lipid, inflammatory and other markers in over 1.1 million participants in 104 prospective studies of cardiovascular diseases. Eur J Epidemiol 2007;22:839-869.

5. Riley RD. Commentary: like it and lump it? Meta-analysis using individual participant data. Int J Epidemiol 2010;39:1359-1361.

Copyright $(2010$ by the American Association for the Study of Liver Diseases. View this article at wileyonlinelibrary.com.

DOI 10.1002/hep.24215

Potential conflict of interest: Nothing to report. 


\section{Noncirrhotic Presinusoidal Portal Hypertension Is Common in Cystic Fibrosis-Associated Liver Disease}

To the Editor:

We read with great interest the article by Lewindon et al., ${ }^{1}$ who demonstrated the importance of liver biopsies in the detection of cystic fibrosis-associated liver disease (CFLD). They demonstrated that in CF complications of portal hypertension can occur before the onset of cirrhosis as determined by liver biopsy. They could partially attribute this to sampling error, although a great effort was made to reduce sampling error by performing dual pass biopsies. However, we are not convinced that sampling error is the main issue. We believe, from Lewindon et al. ${ }^{1}$ and our own findings, that CFLD often presents as noncirrhotic portal hypertension (NCPH) in which the development of portal hypertension precedes that of cirrhosis.

In a retrospective analysis of CF patients of two centers (University Hospitals Leuven, Leuven, Belgium, and Cliniques St Luc, Université Catholique de Louvain, Brussels, Belgium), we gathered biopsies of 12 patients with portal hypertension (10 with esophageal varices, 11 with splenomegaly and thrombocytopenia, and one with previous surgical shunting procedure). Of these 12, there were only five with possible cirrhosis on biopsy. The other seven had varying degrees of fibrosis (F3 in four patients, F2 in one patient, F1 in one patient, and F0 in one patient) and therefore represent NCPH. Four of these seven were scored on liver explants and therefore sampling error certainly did not play a role.

In two of these patients, we were able to perform hemodynamic measurements that revealed a hepatic venous pressure gradient of 5 and $9 \mathrm{~mm} \mathrm{Hg}$, respectively, despite the presence of esophageal varices. This is clear proof of an important presinusoidal component in the portal hypertension consistent with $\mathrm{NCPH}^{2}$ Using this technique, there is also no sampling error.

Portal hypertension out of proportion with the fibrosis suggests $\mathrm{NCPH}$ and therefore an important vascular component. Analysis of our biopsies revealed portal branch venopathy in all the patients with $\mathrm{NCPH}$ (most notably, absence of portal veins in more than $40 \%$ of portal tracts $^{3}$ ) (Fig. 1). These findings were clearly more prevalent in our patients with NCPH than in a reanalyzed control group ${ }^{4}$ of 20 patients with CFLD without portal hypertension $(P=0.008)$ adding to the evidence of a presinusoidal vascular component.

The development of this portal branch venopathy remains obscure. It could be due to spillover of the inflammatory infiltrate
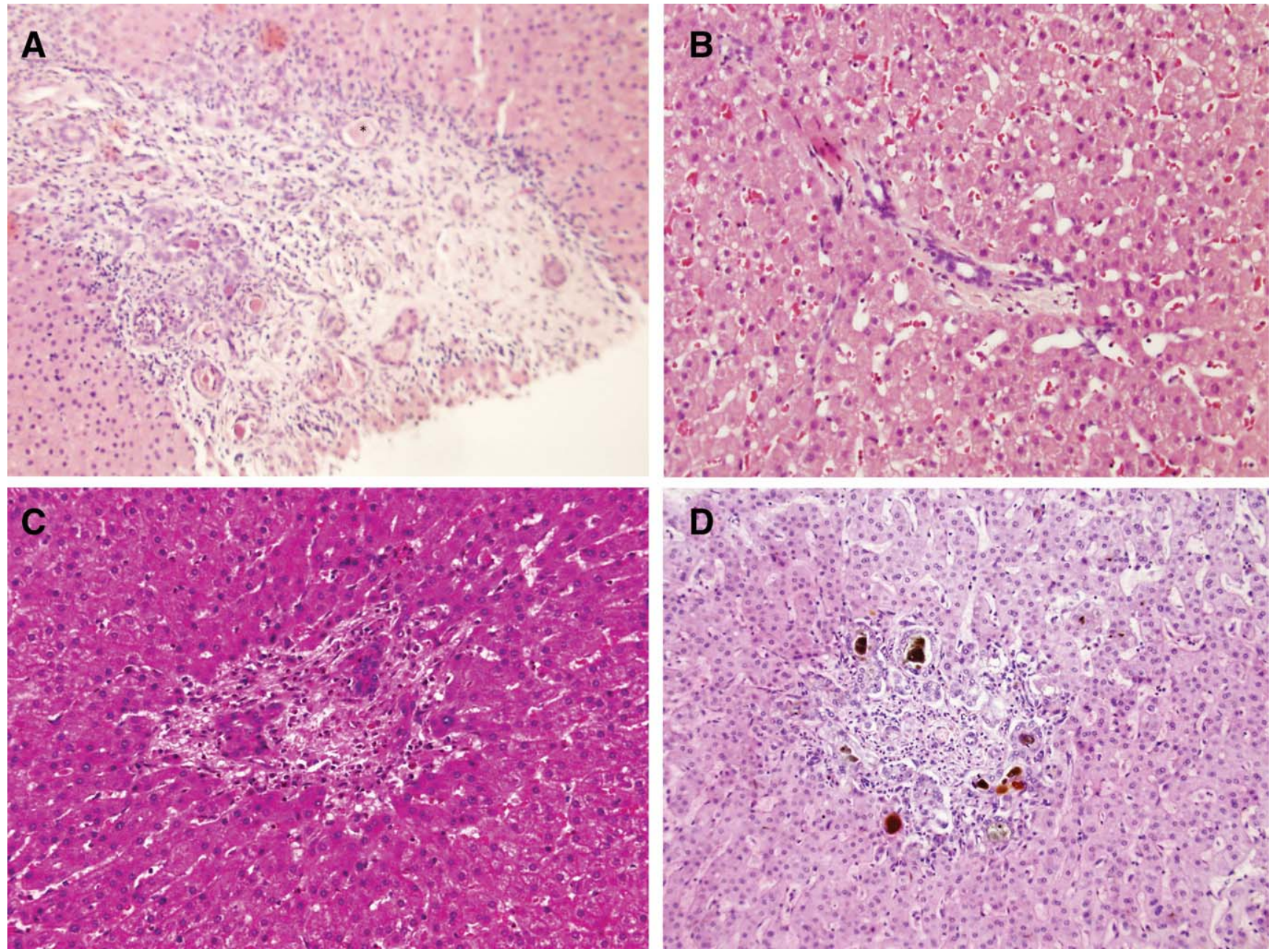

Fig. 1. Portal branch venopathy: absence of portal veins. Hematoxylin-eosin stain of four portal tracts from different liver biopsies of patients with CF (original magnification: $\times 200$ ). None of these portal tracts have demonstrable portal vein branches. Bile inspissations are present in (A; asterix) and (D; brown pigment). Note that (B) has no inflammatory infiltrate. 
of the bile ducts (as suggested in other biliary diseases with presinusoidal portal hypertension ${ }^{5}$ ), due to microthrombosis (platelets are hyperactive in $\mathrm{CF}^{6}$ ), or due to primary endothelialitis ( $\mathrm{CF}$ is associated with a rise in markers of vasculitis ${ }^{7}$ ).

Although the findings of Lewindon et al. and our findings demonstrate the importance of liver biopsies in CF, extreme care must be taken not to underestimate the degree of portal hypertension based on these biopsies. In view of the good hepatic synthetic function, management of patients with CF who have NCPH should probably seek the alleviation of this portal hypertension by shunting procedures (that is, transjugular intrahepatic portosystemic shunt) rather than referring these patients for liver transplantation. Also in that respect, performing liver biopsies and hemodynamic measurements seems indicated.

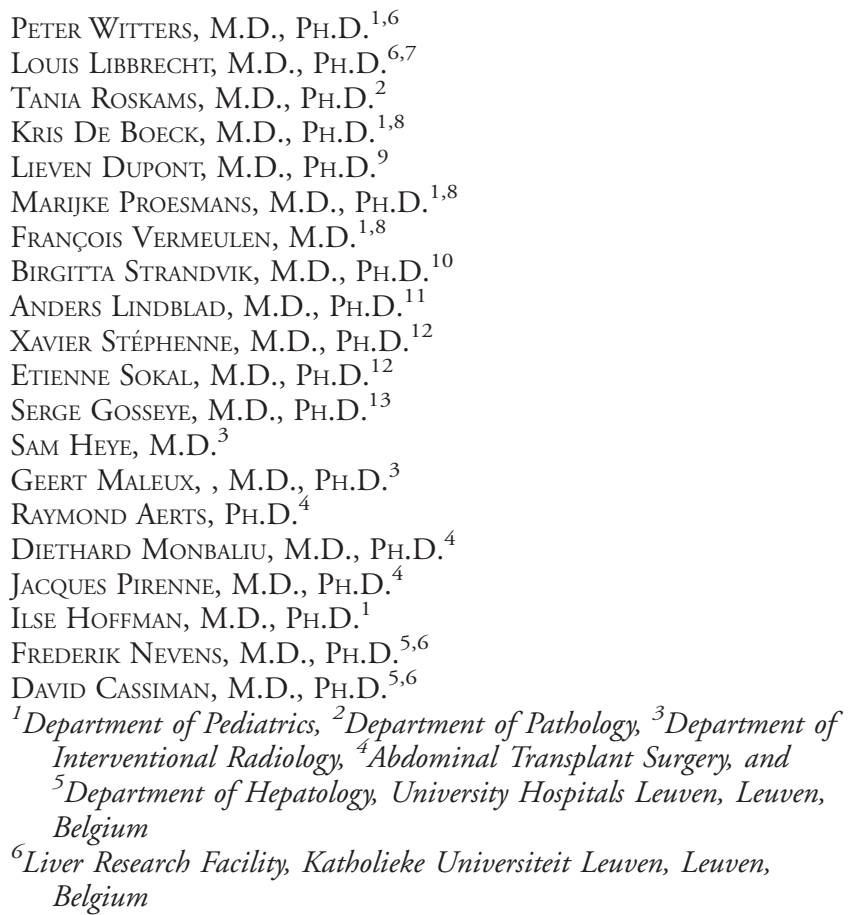

${ }^{7}$ Department of Pathology, Ghent University Hospital, Ghent, Belgium ${ }^{8}$ Department of Pediatrics and ${ }^{9}$ Department of Pulmonology, Cystic Fibrosis Center, University Hospitals Leuven, Leuven, Belgium

${ }^{10}$ Department of Biosciences and Nutrition, NOVUM, Karolinska Institutet, Stockholm, Sweden

${ }^{11}$ Cystic Fibrosis Center, Department of Pediatrics, Sahlgrenska University Hospital, Goteborg, Sweden

${ }^{12}$ Department of Pediatrics and ${ }^{3}$ Department of Pathology, Cliniques St Luc, Université Catholique de Louvain, Brussels, Belgium

\section{References}

1. Lewindon PJ, Shepherd RW, Walsh MJ, Greer RM, Williamson R, Pereira TN, et al. Importance of hepatic fibrosis in cystic fibrosis and the predictive value of liver biopsy. Hepatology 2010; doi:10.1002/ hep. 24014 .

2. Bosch J, Abraldes JG, Berzigotti A, García-Pagan JC. The clinical use of HVPG measurements in chronic liver disease. Nat Rev Gastroenterol Hepatol 2009;6:573-582.

3. Crawford AR, Lin XZ, Crawford JM. The normal adult human liver biopsy: a quantitative reference standard. Hepatology 1998;28:323331.

4. Lindblad A, Glaumann H, Strandvik B. Natural history of liver disease in cystic fibrosis. Hepatology 1999;30:1151-1158.

5. Wanless IR. Understanding noncirrhotic portal hypertension: ménage à fois. Hepatology 1988;8:192-193.

6. O'Sullivan BP, Linden MD, Frelinger AL 3rd, Barnard MR, SpencerManzon M, Morris JE, et al. Platelet activation in cystic fibrosis. Blood 2005;105:4635-4641.

7. Sedivá A, Bartůnková J, Bartosová J, Jennette C, Falk RJ, Jethwa HS. Antineutrophil cytoplasmic antibodies directed against bactericidal/permeability-increasing protein detected in children with cystic fibrosis inhibit neutrophil-mediated killing of Pseudomonas aeruginosa. Microbes Infect 2003;5:27-30

Copyright $(2010$ by the American Association for the Study of Liver Diseases. View this article at wileyonlinelibrary.com. DOI 10.1002/hep.24183

Potential conflict of interest: Nothing to report.

\section{Cystic Fibrosis-Cirrhosis, Portal Hypertension, and Liver Biopsy: Reply}

We welcome the letter by Witters et al. ${ }^{1}$ highlighting the important issue of noncirrhotic portal hypertension (NCPH) in cystic fibrosis (CF). This group's data are complementary to ours, ${ }^{2}$ focusing on liver biopsy findings in 12 patients (ages not supplied), all with established portal hypertension yet only five with established cirrhosis. Of seven cases without cirrhosis, four were from explanted livers permitting direct inspection and avoidance of sampling error. The presinusoidal origin of the portal hypertension was confirmed in two patients who had hepatic venous pressure gradients measured at only 5 and $9 \mathrm{~mm} \mathrm{Hg}$. Witters et al. also report portal venopathy in liver biopsies from all patients classified as $\mathrm{NCPH}$ (whose fibrosis on biopsy did not reach criteria for established cirrhosis), a finding more prevalent than in biopsies from an uncharacterized cohort of 20 children with CF-associated liver disease (CFLD) without portal hypertension.

In our study cohort of 40 patients, a group earlier in the natural history of CFLD with progression of some to advanced portal hypertension (nine at diagnosis and a further eight after 12 years of follow-up), ${ }^{2}$ there was no venopathy reported on biopsy. Two patients in our cohort who subsequently underwent transplantation had established cirrhosis in the explanted liver, and neither had portal venopathy. Portal venopathy is characterized by progressive histological changes, and we suspect that our failure to discern significant venopathy in patients with $\mathrm{NCPH}$ is because biopsy specimens were from patients earlier in the natural history of CFLD. We previously identified markedly increased numbers of activated hepatic stellate cells and myofibroblasts expressing $\alpha$-smooth muscle actin $(\alpha$-SMA) with contractile potential, within portal tracts and around hepatic sinusoids in children with CFLD without fibrosis. ${ }^{3}$ In our more recent study, we reported greatly increased $\alpha$ SMA expression in the biopsies of children with CFLD, which was significantly associated with increasing stage of hepatic fibrosis. ${ }^{2}$ We suspect these contractile cells to have a major role in the development of early NCPH in CFLD.

The findings of Witters et al. give support to the experience of CF centers where development of portal hypertension precedes liver failure by many years or is not followed by failure at all. One child in our study with CF and moderate fibrosis had 
varices, proceeded to splenectomy for severe hypersplenism, and 12 years later continues to have normal liver function (untransplanted).

We agree that care must be taken not to underestimate the degree of portal hypertension based on liver biopsy. Portal hypertension is a dynamic process, where liver biopsy is a snapshot of histology, and severity of portal hypertension and of cirrhosis, although closely related, do not always match up. Witters et al. further highlight the context in which we wish our study to be interpreted. We demonstrated the value of liver biopsy to predict later morbidity and mortality in children suspected as having liver disease, ${ }^{2}$ whereas Witters et al. confirm what we only alluded to: the important role of $\mathrm{NCPH}$ in patients with advanced portal hypertension, particularly those considered for transplantation. ${ }^{1}$ Although sampling error is greatest in patients who are found to have established cirrhosis, the findings of Witters et al. give further support to the role of liver biopsy in CF and may guide clinicians to consider nontransplant alternatives in patients with problematic portal hypertension, particularly if biopsy has revealed the absence of advanced liver damage.

We commend Witters et al. for their important contribution to elucidating the enigma that is CF liver disease and providing further understanding of the role of liver biopsy in this setting.
Peter J. Lewindon, F.R.A.C.P. ${ }^{1,2,3}$

Grant A. Ramm, Ph.D. ${ }^{1}$

${ }^{I}$ The Hepatic Fibrosis Group, The Queensland Institute of Medical Research, ${ }^{2}$ Department of Gastroenterology, Royal Children's Hospital, and ${ }^{3}$ Pediatrics and Child Health. The University of Queensland, Brisbane, Australia

\section{References}

1. Witters P, Libbrecht L, Roskams T, De Boeck K, Dupont L, Proesmans $\mathrm{M}$, et al. Noncirrhotic presinusoidal portal hypertension is common in cystic fibrosis associated liver disease. Hepatology 2011; doi:10.1002/ hep. 24183 .

2. Lewindon PJ, Shepherd RW, Walsh MJ, Greer RM, Williamson R, Pereira TN, et al. Importance of hepatic fibrosis in cystic fibrosis and the predictive value of liver biopsy. Hepatology 2011;53:193-201.

3. Lewindon PJ, Pereira TN, Hoskins AC, Bridle KR, Williamson RM, Shepherd RW, et al. The role of hepatic stellate cells and transforming growth factor-beta (1) in cystic fibrosis liver disease. Am J Pathol 2002; $160: 1705-1715$.

Copyright $\odot 2010$ by the American Association for the Study of Liver Diseases. View this article at wileyonlinelibrary.com. DOI 10.1002/hep.24212

Potential conflict of interest: Nothing to report.

\section{Genotype 4 Hepatitis C Virus: Beware of False-Negative RNA Detection}

\section{To the Editor:}

We have followed with interest the debate regarding the ability of the COBAS AmpliPrep/COBAS TaqMan (CAP/CTM) hepatitis $\mathrm{C}$ virus (HCV) test (Roche, Meylan, France) to accurately detect and quantify genotype $4 \mathrm{HCV}^{1-4}$

We recently identified seven genotype 4 samples [4h (4); $4 \mathrm{k}$ (2); 41 (1)] from HCV antibody-positive patients; we repeatedly found them HCV RNA undetectable with CAP/CTM, but we discovered viral loads greater than $5 \log _{10} \mathrm{IU} / \mathrm{mL}$ with the Abbott RealTime HCV assay (Abbott, Rungis, France). When the $5^{\prime}$-noncoding gene of these undetected samples was compared to sequences from 29 genotype 4 samples [4 (5); 4a (6); 4c (1); 4d (9); $4 \mathrm{f}$ (1); $4 \mathrm{~g}(2) ; 4 \mathrm{~h} \mathrm{(2);} 4 \mathrm{k}(2) ; 4 \mathrm{r}(1)]$, significant sequence differences between underquantified samples (difference between the two assays $>1 \log _{10} \mathrm{IU} / \mathrm{mL}$ ), undetected strains, and samples with comparable viral loads were identified at positions $145(P<$ $0.0001), 165(P<0.0001), 203(P<0.0001)$, and $204(P=$ $0.0002)$ with the chi-square test. Positions 203 and 204 represent a nucleotide insertion in a few subtypes ( $\mathrm{f}, \mathrm{g}, \mathrm{h}, \mathrm{k}, \mathrm{o}, \mathrm{p}$, and $\mathrm{q}$ ) and are unlikely to play a role in CAP/CTM underquantification. However, any mutation at position 145 (rarely described) could dramatically impair the performance of the Roche assay, whereas a mutated nucleotide at position 165 (constantly found in subtypes $\mathrm{g}, \mathrm{h}, \mathrm{k}, \mathrm{l}, \mathrm{m}, \mathrm{o}$, and q) leads to decreased quantification of many genotype 4 subtypes. $2,5,6$

In contrast to the statement by Halfon et al. ${ }^{4}$ on the possible use of CAP/CTM, we would like to stress the risk incurred when this assay is used. ${ }^{4}$ Because highly sensitive real-time polymerase chain reaction-based assays for viral load monitoring are also used as first-line tools to document active HCV replication, our strict recommendation is to not use CAP/CTM to initially identify an active HCV infection or in the case of acute hepatitis because the risk of missing a genuine $\mathrm{HCV}$ infection is not negligible. $^{2}$ Even though the prevalence of particular mutants carrying both 145 and 165 nucleotide substitutions is probably low, it is our duty not to deliver a false reassuring diagnosis of cleared HCV infection.

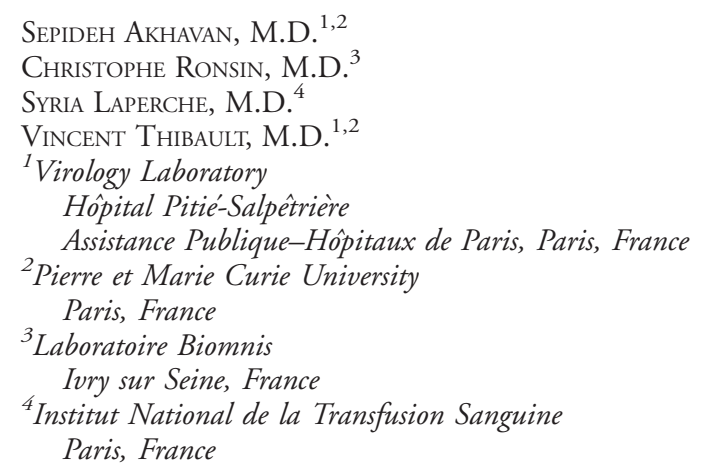

\section{References}

1. Chevaliez S, Bouvier-Alias M, Castéra L, Pawlotsky JM. The Cobas AmpliPrep-Cobas TaqMan real-time polymerase chain reaction assay fails to detect hepatitis $\mathrm{C}$ virus RNA in highly viremic genotype 4 clinical samples. Hepatology 2009;49:1397-1398.

2. Chevaliez S, Fix J, Soulier A, Pawlotsky JM. Underestimation of hepatitis $\mathrm{C}$ virus genotype 4 RNA levels by the Cobas AmpliPrep/Cobas TaqMan assay. Hepatology 2009;50:1681-1681.

3. Germer JJ, Bommersbach CE, Schmidt DM, Bendel JL, Yao JDC. Quantification of genotype 4 hepatitis C virus RNA by the COBAS AmpliPrep/COBAS TaqMan hepatitis C virus test. Hepatology 2009; 50:1679-1680.

4. Halfon P, Martinot-Peignoux M, Khiri H, Marcellin P. Quantification of genotype 4 serum samples: impact of hepatitis $\mathrm{C}$ virus genetic variability. Hepatology 2010;52:401. 
5. Chevaliez S, Bouvier-Alias M, Brillet R, Pawlotsky JM. Overestimation and underestimation of hepatitis C virus RNA levels in a widely used real-time polymerase chain reaction-based method. Hepatology 2007; 46:22-31.

6. Sarrazin C, Gartner BC, Sizmann D, Babiel R, Mihm U, Hofmann WP, et al. Comparison of conventional PCR with real-time PCR and branched DNA-based assays for hepatitis C virus RNA quantification and clinical significance for genotypes 1 to 5. J Clin Microbiol 2006;44: 729-737.

Copyright (C) 2010 by the American Association for the Study of Liver Diseases.

View this article at wileyonlinelibrary.com.

DOI 10.1002/hep.23975

Potential conflict of interest: Nothing to report.

\section{On the Mechanism of Action of Vitamin E for Nonalcoholic Steatohepatitis}

\section{To the Editor:}

Nonalcoholic steatohepatitis (NASH) is a serious form of nonalcoholic fatty liver disease and can progress to cirrhosis. A recent clinical study reported that the most important lipophilic antioxidant, vitamin E, was superior to a placebo for the treatment of NASH in adults without diabetes. ${ }^{1}$ Dufour $^{2}$ has provided comprehensive comments on the findings and particularly on the mechanism of action of vitamin E for NASH.

Natural vitamin E exists in eight natural analogues: four tocopherols $(\alpha$-tocopherol, $\beta$-tocopherol, $\gamma$-tocopherol, and $\delta$-tocopherol) and four tocotrienols ( $\alpha$-tocotrienol, $\beta$-tocotrienol, $\gamma$-tocotrienol, and $\delta$-tocotrienol). Because of the significant role of oxidative stress in NASH pathogenesis, the prevailing view is that antioxidant activity should be the main mechanism of action of vitamin E. However, the antioxidant mechanism of vitamin $\mathrm{E}$ is doubted by Dufour $^{2}$ because the eight analogues possess equal antioxidant potency and yet individually lead to type-specific cellular outcomes. However, we think that the type-specific cellular outcomes do not disprove the antioxidant mechanism of vitamin $\mathrm{E}$ in the treatment of NASH. The different cellular outcomes for vitamin $\mathrm{E}$ analogues may arise from their different antioxidant characters and especially from the variance in the free-radical species that they can scavenge. ${ }^{3-5} \alpha$-Tocopherol possesses a strong reactive oxygen species-scavenging ability. In comparison, it has been proved that $\gamma$ tocopherol is more nucleophilic and thus is more efficient than $\alpha$ tocopherol in scavenging reactive nitrogen species. ${ }^{3-5}$ For instance, Christen et al. ${ }^{4}$ investigated the efficacy of $\alpha$-tocopherol and $\gamma$-tocopherol in inhibiting peroxynitrite-induced lipid peroxidation and found that the two tocopherols showed fundamentally different abilities and that $\gamma$-tocopherol was more effective than $\alpha$-tocopherol. Cooney et al. ${ }^{5}$ reported that nitrogen dioxide-mediated nitrosation of morpholine could be inhibited effectively only by $\gamma$-tocopherol and not by $\alpha$-tocopherol. Thus, the different antioxidant characters of the vitamin $\mathrm{E}$ analogues may account, at least in part, for the type-specific cellular outcomes. The antioxidant mechanism of vitamin E certainly does not conflict with other pathways, and we also agree with the regulation of signaling enzymes by a vitamin E-associated mechanism as proposed by Dufour.
Even though the mechanism of action of vitamin E for NASH may be complicated, operating under the premise of an antioxidant mechanism, we should devote more effort to enhancing its antioxidant capacity (e.g., through its combination with other antioxidants) with the aim of further increasing the rate of $\mathrm{NASH}$ improvement with vitamin E therapy.

\author{
Hong-Fang Ji, Ph.D \\ LiAng Shen, PH.D \\ Shandong Provincial Research Center for \\ Bioinformatic Engineering and Technique \\ Shandong University of Technology \\ Zibo, People's Republic of China
}

\section{References}

1. Sanyal AJ, Chalasani N, Kowdley KV, McCullough A, Diehl AM, Bass NM, et al. Pioglitazone, vitamin E, or placebo for nonalcoholic steatohepatitis. N Engl J Med 2010;362:1675-1685.

2. Dufour JF. Vitamin E for nonalcoholic steatohepatitis: ready for prime time? Hepatology 2010;52:789-792.

3. Cooney RV, Harwood PJ, Franke AA, Narala K, Sundström A-K, Berggren $\mathrm{P}-\mathrm{O}$, et al. Products of $\gamma$-tocopherol reaction with $\mathrm{NO}_{2}$ and their formation in rat insulinoma (RINm5F) cells. Free Radic Biol Med 1995; 19:259-269.

4. Christen S, Woodall AA, Shigenaga MK, Southwell-Keely PT, Duncan MW, Ames BN. $\gamma$-Tocopherol traps mutagenic electrophiles such as NOx and complements $\alpha$-tocopherol: physiological implications. Proc Natl Acad Sci U S A 1997;94:3217-3222.

5. Cooney RV, Franke AA, Harwood PJ, Hatch-Pigott V, Custer LJ, Mordan LJ. $\gamma$-Tocopherol detoxification of nitrogen dioxide: superiority to ๔-tocopherol. Proc Natl Acad Sci U S A 1993;90:1771-1775.

Copyright $\odot 2010$ by the American Association for the Study of Liver Diseases. View this article at wileyonlinelibrary.com. DOI 10.1002/hep.23950

Potential conflict of interest: Nothing to report.

\section{Early Determination of Hepatitis C Virus RNA May Help to Decide the Duration of Therapy for Chronic Hepatitis C Virus Genotype 2/3 Infection}

\section{To the Editor:}

Diago et al. ${ }^{1}$ reported results for genotype $2 / 3$-infected patients treated for at least $80 \%$ of the planned duration in the a randomized, open-label study of the effect of PEGASYS and ribavirin combination therapy on sustained virologic response in interferonnaive patients with chronic hepatitis $\mathrm{C}$ genotype 2 or 3 infection (ACCELERATE) trial. Among patients achieving a rapid virological response [RVR; i.e., undetectable hepatitis $\mathrm{C}$ virus (HCV) RNA after 4 weeks of therapy according to an assay with a limit 
of detection of $<50 \mathrm{IU} / \mathrm{mL}$ ], sustained virological response (SVR) rates of $82 \%$ and $91 \%$ were observed for patients treated for 16 and 24 weeks, respectively. When this analysis was restricted to patients with a baseline viral load less than or equal to $400,000 \mathrm{IU} / \mathrm{mL}(25 \%$ of all patients), the SVR rates were $91 \%$ and $95 \%$, respectively.

We recently presented results from a trial of HCV genotype 2/3infected patients (the NORDynamIC study; $\mathrm{n}=382$ ) who received peginterferon alfa-2a weekly plus $800 \mathrm{mg}$ of ribavirin daily for 12 or 24 weeks. Serial HCV RNA samples were analyzed with reverse-transcription polymerase chain reaction with a limit of detection of $<15$ $\mathrm{IU} / \mathrm{mL}^{2}{ }^{2}$ Three hundred three patients $(79 \%)$ received at least $80 \%$ of the target doses of peginterferon alfa- $2 \mathrm{a}$ and ribavirin for at least $80 \%$ of the target treatment duration, and they were thus included in a per protocol analysis. In comparison with 12 weeks of treatment, 24 weeks of treatment resulted in higher SVR rates in patients with undetectable HCV RNA $(P<0.0001$, chi-square test and Fisher's exact test), in patients with HCV RNA levels of $15-50 \mathrm{IU} / \mathrm{mL}(P=$ 0.02 , Fisher's exact test), and in patients with HCV RNA levels $<50$ $\mathrm{IU} / \mathrm{mL}$ on day $29(P=0.009$, Fisher's exact test). When this analysis was restricted to patients with a baseline viral load less than or equal to $400,000 \mathrm{IU} / \mathrm{mL}(\mathrm{n}=73)$, as suggested by Diago et al., ${ }^{1} 35$ of 37 patients (95\%) in the 12-week study arm achieved SVR, whereas 36 of 36 patients $(100 \%)$ in the 24-week arm achieved SVR. These results support the idea that short-term therapy is suitable for patients with low baseline viral loads who achieve RVR and do not require major dose reductions.

However, the algorithm proposed by Diago et al. ${ }^{1}$ requires two HCV RNA analyses (at the baseline and in week 4). The results of the NORDynamIC trial imply that a single HCV RNA analysis with a cutoff level of $1000 \mathrm{IU} / \mathrm{mL}$ on day 7 predicts SVR as accurately as RVR and identifies at least as many candidates suitable for short-term therapy (28\% versus $25 \%$ for the algorithm proposed by Diago et al.). Also, the suggested cutoff level of $1000 \mathrm{IU} / \mathrm{mL}$ is stably quantifiable by most currently available assays and is not prone to redefinition as the limits of detection of HCV RNA analyses further improve over time.

Martin LagGing, M.D. ${ }^{1}$

Åsa Alsiö, M.D.

Nina Langeland, M.D. ${ }^{2}$

Court Pedersen, M.D. ${ }^{3}$

MartTI FärkKilä, M.D. ${ }^{4}$

Mads Rauning Buhl, M.D. 5

\author{
Kristine MørCh, M.D. ${ }^{2}$ \\ Kristoffer Hellstrand, M.D. ${ }^{1}$ \\ Gunnar Norkrans, M.D. ${ }^{1}$ \\ ${ }^{1}$ Department of Infectious Diseases \\ Gothenburg University \\ Gothenburg, Sweden \\ ${ }^{2}$ Department of Infectious Diseases \\ Haukeland University Hospital and Institute of Medicine \\ University of Bergen, Bergen, Norway \\ ${ }^{3}$ Department of Infectious Diseases \\ University of Southern Denmark \\ Odense, Denmark \\ ${ }^{4}$ Department of Gastroenterology \\ Helsinki University \\ Helsinki, Finland \\ ${ }^{5}$ Department of Infectious Diseases \\ Aarhus University \\ Aarhus, Denmark
}

\section{References}

1. Diago M, Shiffman ML, Bronowicki JP, Zeuzem S, Rodriguez-Torres M, Pappas SC, et al. Identifying hepatitis C virus genotype $2 / 3$ patients who can receive a 16 -week abbreviated course of peginterferon alfa-2a (40KD) plus ribavirin. Hepatology 2010;51:18971903.

2. Lagging M, Langeland N, Pedersen C, Farkkila M, Buhl MR, Morch K, et al. Randomized comparison of 12 or 24 weeks of peginterferon alpha-2a and ribavirin in chronic hepatitis $\mathrm{C}$ virus genotype $2 / 3$ infection. Hepatology 2008;47:1837-1845.

The Swedish Society of Medicine, the Swedish Medical Research Council, the Torsten and Ragnar Söderberg Foundation, Cancerfonden, the Swedish Society of Microbiology, Avtal om läkarutbildning och forskning (ALF) funds, and Roche affiliates in the Nordic region supported this study.

This letter was written for the NORDynamIC study group.

Copyright $(2010$ by the American Association for the Study of Liver Diseases. View this article at wileyonlinelibrary.com.

DOI 10.1002/hep.23962

Potential conflict of interest: Dr. Färkkilä consults for and advises Roche. He is consults for, advises, and received grants from MSD.

\section{Effects of Beta-Blockers on Survival for Patients With Cirrhosis and Refractory Ascites}

\section{To the Editor:}

I read with interest the article by Serste et al., ${ }^{1}$ who showed that beta-blockers are deleterious to the survival of patients with cirrhosis and refractory ascites. Because the study was performed with two groups of patients with cirrhosis with striking differences in their characteristics, it should be interpreted with caution. As indicated in the editorial by Wong and Salerno, ${ }^{2}$ the patients on beta-blockers were indeed sicker: they had higher bilirubin levels, lower albumin levels, lower arterial pressures, and lower serum sodium levels, and more patients had hepatic encephalopathy, hepatocellular carcinoma, and Child-Pugh class $\mathrm{C}$ cirrhosis. In addition, the patients receiving beta-blockers were taking them for the prevention of variceal hemorrhaging, but only $4 \%$ of the patients not receiving beta-blockers had esophageal varices. I do not know whether the patients received beta-blockers mainly for primary or secondary prevention of variceal bleeding. If patients had episodes of variceal bleeding with concomitant refractory ascites and hepatocellular carcinoma, the outcome was naturally very dismal. More- over, Serste et al. did not disclose the proportions of (1) hepatitis $\mathrm{B}$ patients receiving antiviral treatment, (2) alcoholic patients who were abstinent, and (3) patients whose refractory ascites was managed with transjugular intrahepatic portosystemic stent shunts in the two groups. All these factors may partly influence the outcomes of patients with advanced cirrhosis. ${ }^{3,4}$ The causes of death in the two groups were not revealed in detail. As many as 25 patients (17\%) died at home of unspecified causes. It is generally believed that the use of beta-blockers is contraindicated in patients with hypotension or bradycardia. However, some patients with hypotension or bradycardia were still enrolled in the beta-blocker group. This appears to be against the principle of using propranolol to prevent gastrointestinal hemorrhaging. ${ }^{5}$ My group has previously shown that patients receiving medical therapy have improved survival in comparison with those receiving endoscopic ligation to prevent variceal rebleeding. ${ }^{6}$ For patients with cirrhosis, refractory ascites, and a high risk of variceal bleeding, controlled trials are still required to compare the efficacy and safety of beta-blockers and endoscopic ligation; otherwise, liver transplantation will be needed. 
GIN-Ho Lo, M.D.

Department of Medical Nutrition

I-Shou University

Kaohsiung, Taiwan

\section{References}

1. Serste T, Melot C, Durand F, Rautou PE, Valla D, Moreau R, et al. Deleterious effects of beta-blockers on survival in patients with cirrhosis and refractory ascites. Hepatology 2010;52:1017-1022.

2. Wong F, Salerno F. Beta-blockers in cirrhosis: friend and foe? HepatoLOGY 2010;52:811-813.

3. Runyon BA. Management of adult patients with ascites due to cirrhosis: an update. Hepatology 2009;49:2087-2107.
4. Lo GH. The management of cirrhotic ascites. Hepatology 2009;50: 1320.

5. Lebrec D, Poynard T, Hillon P, Benhamou J-P. Propranolol for prevention of recurrent gastrointestinal bleeding in patients with cirrhosis: a controlled study. N Engl Med 1981;305:1371-1374.

6. Lo GH, Chen WC, Lin CK, Tsai WL, Chan HH, Chen TA. Improved survival in patients receiving medical therapy as compared with banding ligation for the prevention of esophageal variceal rebleeding. HePATOLOGY 2008; $48: 580-587$.

Copyright $(\subseteq 2010$ by the American Association for the Study of Liver Diseases. View this article at wileyonlinelibrary.com. DOI 10.1002/hep.23986

Potential conflict of interest: Nothing to report.

\section{Activation of the Endotoxin/Toll-Like Receptor 4 Pathway: The Way to Go From Nonalcoholic Steatohepatitis up to Hepatocellular Carcinoma}

\section{To the Editor:}

We read with great interest the article by $\mathrm{Yu}$ et al. ${ }^{1}$ on the role of gut-derived endotoxin in hepatocarcinogenesis. In particular, the authors demonstrated that increased levels of endotoxemia observed in an experimental animal model of chemically induced hepatocarcinogenesis, were protective against liver cell apoptosis and seemed to promote the development of hepatocellular carcinoma (HCC). In fact, $\mathrm{Yu}$ et al. found that treatment with antibiotics partially protected rats from diethylnitrosamine-induced hepatocarcinogenesis, which reduced the number of tumors and their maximum size. In addition, the animals treated with antibiotics showed decreased plasma levels of lipopolysaccharide (LPS) and hepatic levels of tumor necrosis factor $\alpha$ and interleukin- 6 messenger RNA. Interestingly, diethylnitrosamine-induced HCC was reduced in toll-like receptor 4 (TLR4) mutant mice, and they displayed a lower incidence of tumors and a smaller maximum tumor size associated with reduced infiltration of macrophages with respect to the control animals.

The authors hypothesized that LPS could promote survival signaling by TLR4; this would allow tumor cells to escape apoptosis, induce compensatory proliferation in hepatocytes, and lead to HCC. It is well known that the development and progression of HCC can depend on several etiological factors, including viral infections, alcohol abuse, and nonalcoholic steatohepatitis (NASH) ${ }^{2,3}$ Often, all these factors coexist; this leads to more rapid progression of the liver disease and increases the risk for HCC. Interestingly, recent studies have shown that the gut-liver axis and particularly gut-derived endotoxin seem to play crucial roles in the pathogenesis of chronic inflammatory liver diseases such as NASH. ${ }^{4}$ Although the real molecular mechanisms are still unknown, undoubtedly the activation of the endotoxin/TLR4 signaling pathway is pivotal to the pathogenic effect of the proinflammatory immune response in NASH. ${ }^{5}$

All these findings reinforce the idea that the crucial balance existing between gut microbial flora, intestinal permeability, the innate immune response, hepatocyte function, and Kupffer cell activation is decisive in the maintenance of liver cell homeostasis. However, Yu et al. ${ }^{1}$ add to this puzzle a novel piece of relevant information about potential mechanisms leading to HCC. In fact, by enhancing proinflammatory signals, LPS-dependent TLR4 activity possibly may not only favor progression from NASH to fibrosis but also trigger HCC next. We believe that this last point especially should make us reflect on the relevance of the innate immune pathogenesis of several chronic liver diseases and HCC.

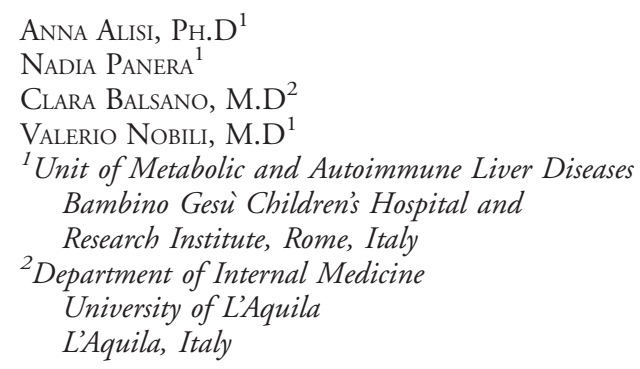

\section{References}

1. Yu LX, Yan HX, Liu Q, Yang W, Wu HP, Dong W, et al. Endotoxin accumulation prevents carcinogen-induced apoptosis and promotes liver tumorigenesis in rodents. Hepatology 2010;52:1322-1333.

2. Morgan TR, Mandayam S, Jamal MM. Alcohol and hepatocellular carcinoma. Gastroenterology 2004;127(Suppl 1):87-96.

3. Starley BQ, Calcagno CJ, Harrison SA. Nonalcoholic fatty liver disease and hepatocellular carcinoma: a weighty connection. HePATOLOGY 2010; 51:1820-1832.

4. Valenti L, Fracanzani AL, Fargion S. The immunopathogenesis of alcoholic and nonalcoholic steatohepatitis: two triggers for one disease? Semin Immunopathol 2009;31:359-369.

5. Alisi A, Panera N, Nobili V. Toll-like receptor 4: a starting point for proinflammatory signals in fatty liver disease. HePATOLOGY 2010;51: 714-715.

Copyright (C) 2010 by the American Association for the Study of Liver Diseases. View this article at wileyonlinelibrary.com.

DOI 10.1002/hep.24003

Potential conflict of interest: Nothing to report. 


\section{Necrosis Versus Apoptosis in Acetaminophen-Induced Hepatotoxicity}

\section{To the Editor:}

We read with interest the article by $\mathrm{Hu}$ and Colletti investigating the mechanisms of acetaminophen ( $N$-acetyl-para-aminophenol [APAP])-induced liver injury. ${ }^{1}$ The authors suggest that APAP hepatotoxicity is caused by the mitochondrial apoptosis pathway and facilitated by chemokine (C-X-C motif) receptor 2 (CXCR2) receptor signaling. We would like to bring to the readers' attention that, due to the increasing knowledge of nonapoptotic cell death and the development of novel biomarkers, recent evidence indicates that acute liver failure (ALF) following an APAP overdose is mainly mediated by necrosis rather than by apoptosis. ${ }^{2,3}$ Moreover, we have reported that not only in experimental models, but even in critically ill patients with ALF, necrosis is the predominant cause of APAP hepatotoxicity. ${ }^{4}$ A distinction between both cell death mechanisms is important, because there are now increasing possibilities for therapeutic interventions with these distinct cell death forms. Results from our and other groups further suggest that determination of the mode of cell death might be of predictive value for the disease outcome of patients with ALF. ${ }^{4-6}$

The mechanism of APAP-induced liver injury involves the generation of the toxic metabolite $N$-acetyl-p-benzoquinoneimine by the cytochrome P450 system, which causes glutathione depletion, oxidative stress, alterations of calcium homeostasis, and finally results in mitochondrial damage and adenosine triphosphate (ATP) depletion. However, even though mild forms of APAP intoxication might cause signs of apoptosis, there is now a general agreement that apoptosis is strictly ATP-dependent and therefore inhibited under conditions of ATP depletion. Instead, necrosis as a result of mitochondrial dysfunction is consistent with high lactate levels that are especially observed in patients with ALF with a poor outcome. ${ }^{8}$

Unfortunately, the methods used by $\mathrm{Hu}$ and Colletti preclude the evaluation of the relevant cell death pathways, but might have led to the misinterpretation of apoptosis as the principal mechanism of APAP hepatotoxicity. First, the authors show that a caspase inhibitor, which was solubilized in dimethylsulfoxide (DMSO), prevented terminal deoxynucleotidyl transferase-mediated deoxyuridine triphosphate nick-end labeling (TUNEL) staining in hepatocytes. TUNEL is an unspecific marker that cannot distinguish between apoptotic and necrotic DNA fragmentation. Moreover, a DMSO control was not presented but is mandatory, because DMSO is a radical scavenger and by itself exerts cytoprotective effects. ' Second, although the authors show that APAP-induced DNA fragmentation was prevented, it remains unclear whether caspase inhibition indeed improves the survival of mice. There are many cases known in which caspase inhibitors prevent apoptotic alterations but do not affect cell survival. Finally, on the basis of the assessment of proteolytic caspase fragments, the authors suggest that caspase- 9 is activated by APAP. However, they do not present data on the enzymatic caspase activity. Indeed, caspase-9 does not require cleavage to be activated. Moreover, calpains that are activated by APAP can induce proteolytic cleavage of caspase9. ${ }^{10}$ These cleavages generate fragments of similar size but occur at sites that render the caspase- 9 proteolytically inactive. Hence, the mere cleavage of caspase- 9 cannot be taken as sufficient evidence for its activation.

Altogether, we have serious concerns regarding the interpretation of the results by $\mathrm{Hu}$ and Colletti. Apoptosis is certainly of major importance in many chronic liver diseases. APAP-induced ALF is, however, one of the few examples where necrosis but not apoptosis predominates. An understanding of the cell death processes will be essential for effective interventions in ALF and other liver diseases.

\author{
Klaus Schulze-Osthoff, M.D ${ }^{1}$ \\ HeIKe BANTEL, M.D ${ }^{2}$ \\ ${ }^{1}$ Interfaculty Institute for Biochemistry, University of Tübingen, \\ Tübingen, Germany \\ ${ }^{2}$ Department of Gastroenterology, Hepatology, and Endocrinology, \\ Hannover Medical School, Hannover, Germany
}

\section{References}

1. Hu B, Colletti LM. CXC receptor-2 knockout genotype increases Xlinked inhibitor of apoptosis protein and protects mice from acetaminophen hepatotoxicity. Hepatology 2010;52:691-702.

2. Jaeschke H, Bajt ML. Intracellular signaling mechanisms of acetaminophen-induced liver cell death. Toxicol Sci 2006;89:31-41.

3. Malhi H, Gores GJ. Cellular and molecular mechanisms of liver injury. Gastroenterology 2008;134:1641-1654.

4. Volkmann X, Anstaett M, Hadem J, Stiefel P, Bahr MJ, Lehner F, et al. Caspase activation is associated with spontaneous recovery from acute liver failure. Hepatology 2008;47:1624-1633.

5. Hofer S, Brenner T, Bopp C, Steppan J, Lichtenstern C, Weitz J, et al. Cell death serum biomarkers are early predictors for survival in severe septic patients with hepatic dysfunction. Crit Care 2009;13:R93.

6. Bechmann LP, Marquitan G, Jochum C, Saner F, Gerken G, Canbay A. Apoptosis versus necrosis rate as a predictor in acute liver failure following acetaminophen intoxication compared with acute-on-chronic liver failure. Liver Int 2008;28:713-716.

7. Leist M, Single B, Castoldi AF, Kuhnle S, Nicotera P. Intracellular adenosine triphosphate (ATP) concentration: a switch in the decision between apoptosis and necrosis. J Exp Med 1997;185:1481-1486.

8. Bernal W, Donaldson N, Wyncoll D, Wendon J. Blood lactate as an early predictor of outcome in paracetamol-induced acute liver failure: a cohort study. Lancet 2002;359:558-563.

9. Yu ZW, Quinn PJ. Dimethyl sulphoxide: a review of its applications in cell biology. Biosci Rep 1994;14:259-281.

10. Wolf BB, Goldstein JC, Stennicke HR, Beere H, Amarante-Mendes GP, Salvesen GS, et al. Calpain functions in a caspase-independent manner to promote apoptosis-like events during platelet activation. Blood 1999;94:1683-1692.

Copyright $(2010$ by the American Association for the Study of Liver Diseases. View this article at wileyonlinelibrary.com. DOI 10.1002/hep.24027

Potential conflict of interest: Nothing to report.

\section{Is Achievement of Sustained Virologic Response an Independent Predictor or a Cofactor for the Development of Esophageal Varices?}

\section{To the Editor:}

We read with great interest the study by Bruno et al., which concluded that achievement of sustained virologic response prevents the development of esophageal varices in patients with compensated hepatitis C virus (HCV)-induced cirrhosis. Their multivariable analysis also showed that $\mathrm{HCV}$ genotype $1 \mathrm{~b}$ is an independent predictor for the development of esophageal varices. ${ }^{1}$ The interpretation of the results, however, raises a concern. 
It is well known that the clinical outcome of antiviral therapy is significantly influenced by viral genotype. ${ }^{2,3}$ That is to say, patients with different HCV genotypes may have different responses to the antiviral therapy. This is confirmed by the observation that patients infected with genotype $1 \mathrm{~b}$ have lower rate of sustained virologic response. ${ }^{1}$ Therefore, HCV genotype $1 \mathrm{~b}$ may be more likely to be an independent predictor for the development of esophageal varices, and achievement of sustained virologic response may be merely a cofactor associated with the host response to antiviral therapy. Further study is needed to clarify this concern.

Li-Ping Ye, M.D.

Xin-Li MaO, M.D.

Department of Gastroenterology

Taizhou Hospital of Zhejiang Province

Linhai, China

\section{References}

1. Bruno S, Crosignani A, Facciotto C, Rossi S, Roffi L, Redaelli A, et al. Sustained virologic response prevents the development of esophageal varices in compensated, Child-Pugh class A hepatitis C virus-induced cirrhosis. A 12year prospective follow-up study. HEPATOLOGy 2010;51:2069-2076.

2. Taliani G, Badolato MC, Pasquazzi C. Hepatitis $C$ virus genotype, hepatitis $C$ virus RNA titers, and response to interferon. Ann Intern Med 1997;127:89.

3. Zein NN, Rakela J, Krawitt EL, Reddy KR, Tominaga T, Persing DH. Hepatitis C virus genotypes in the United States: epidemiology, pathogenicity, and response to interferon therapy. Collaborative Study Group. Ann Intern Med 1996;125:634-639.

Copyright $(0) 2010$ by the American Association for the Study of Liver Diseases. View this article at wileyonlinelibrary.com.

DOI 10.1002/hep.24026

Potential conflict of interest: Nothing to report. 